\title{
Nonlinear flexural behaviour of RC columns including bar buckling and fatigue degradation
}

\author{
Mohammad M Kashani ${ }^{1}$, Mohammad R Salami ${ }^{2}$, Katsuichiro Goda ${ }^{3}$, Nicholas A Alexander ${ }^{4}$
}

Abstract

An advanced fibre-based modelling technique is developed to characterise the nonlinear flexural behaviour of rectangular reinforced concrete (RC) columns by accounting for the influence of inelastic buckling and low-cycle fatigue degradation of vertical reinforcement. The proposed uniaxial material model of reinforcing steel is calibrated using 22 rectangular RC column tests. The influence of inelastic buckling of vertical reinforcement on the nonlinear cyclic response of rectangular $\mathrm{RC}$ columns is investigated. The calibrated model is capable of accurately predicting the nonlinear response of rectangular RC columns up to complete collapse by taking into account the additional failure modes of the RC columns.

Keywords: Finite element methods, Reinforcement, Fatigue, Failure, Modelling

\section{Introduction}

The modern seismic design practice has improved the seismic response of reinforced concrete (RC) structures under earthquake loading when compared to older structures. Nevertheless, destructive damage has been observed in recent large earthquakes and financial loss due to such events can be devastating (Mander and Rodgers 2015). This is the consequence of designing structures for ductility. In other words, structures are design for a reduced strength to a specific seismic hazard level. The RC structures are the prescriptively detailed in their potential plastic hinge locations for ductility. However, at the time when these codes were written, the adverse effect of low-cycle fatigue combined with inelastic buckling of longitudinal reinforcement on performance of RC structures (Mander and Rodgers 2015) were not very well understood. Furthermore, the existing performance-based earthquake engineering (PBEE) relates structural damage to the economic impact to promote risk mitigation decisions (Moehle and Dierlein 2004). It requires accurate response models to predict the seismic demand of RC structures under multiple hazard levels and suitable damage models that relate to the consequences of the earthquake damage. Finally, the PBEE framework links the

\footnotetext{
${ }^{1}$ Lecturer, University of Southampton, Faculty of Engineering and Environment, Southampton, SO17 1BJ, UK (corresponding author), Email: mehdi.kashani@soton.ac.uk

${ }^{2} \mathrm{PhD}$ Candidate, University of Bristol, Dept. of Civil Engineering University of Bristol, Bristol, BS8 1TR, United Kingdom

${ }^{3}$ Senior Lecturer, University of Bristol, Dept. of Civil Engineering University of Bristol, Bristol, BS8 1TR, United Kingdom

${ }^{4}$ Senior Lecturer, University of Bristol, Dept. of Civil Engineering University of Bristol, Bristol, BS8 1TR, United Kingdom
} 
structure/component demands with damage state to estimate the economic loss. Accordingly, several researchers (Berry and Eberhard 2003, 2005; Lehman and Moehle 2004) have studied the relationships between the demand parameters, such as drift ratio or strain at critical section, and damage parameters, such as cover concrete spalling, bar buckling and low-cycle fatigue degradation, experimentally.

The 2010-2011 Christchurch earthquake revealed that if an earthquake event occurs and results in a visible damage in the structure, it is very likely that the cyclic degradation of that event (with or without the effect of buckling) may have consumed some of the available fatigue life of the structure. Moreover, if several large earthquakes in a sequence have occurred (mainshock-aftershock sequence), the owner is in a quandary regarding the service life of the asset. Therefore, the owner might be require to restore the asset to a pre-earthquake damage condition. Given the low-cycle fatigue and buckling are permanent damage, the damaged components and their associated connections within the structure may be required to be reconstructed with new materials. Accordingly, there is an urgent need for advanced computational tools to predict the performance of existing structures subject to large earthquake events.

Recent advances in computational tools have improved the capability of finite element (FE) modelling techniques in nonlinear analysis of structures subjected to earthquake loading. Among the recent advanced methods, a fibre-based FE technique using a distributed-plasticity beam-column model and lumped-plasticity model are widely used. In the fibre model, the element cross section is discretised into a number of fibres. The material nonlinearity is represented by assigning nonlinear uniaxial material models to concrete and reinforcing steel. In the lumped-plasticity model, nonlinearity of a beam-column element is introduced at the two ends of the element (i.e. hinges) using nonlinear springs, which are connected by an elastic beam-column element. Ibarra et al. (2005) and Haselton et al. (2011) showed that when a suitable hysteretic model is assigned to the springs, the lumped-plasticity model can predict the nonlinear behaviour of RC elements reasonably well. However, the problem of this approach is that the hysteretic model needs to be calibrated against certain experimental data in every single element/structure and cannot be generalised to other cases. Furthermore, once the lumped-plasticity is calibrated against a set of experimental data, it does not capture the different failure modes of RC components. More importantly, a calibrated lumpedplasticity model might be able to simulate the cyclic degradation of an RC component but still cannot capture the remaining low-cycle fatigue life (in case of partial damage) of that component after a given cyclic load history. In contrast, the distributed-plasticity approach using nonlinear fibre beamcolumn elements, once their material models are calibrated, can be applied to various cases, and thus are not constrained by specific test data. However, the conventional nonlinear fibre beam-column 
element models (Taucer et al. 1991; Spacone et al. 1996a, b) are not capable of simulating the cyclic deterioration of $\mathrm{RC}$ components due to reinforcement buckling, low-cycle fatigue degradation and concrete crushing. In order to improve this, other researchers (Monti and Nuti 1992; Rodriguesz et al. 1999; Gomes and Appleton 1997; Dhakal and Maekawa 2002a; Kunnath et al. 2009; Bae et al. 2005; Kashani et al. 2015a,b Kashani 2014) have developed uniaxial material models that can capture inelastic buckling behaviour of reinforcing bars with and without the effect of low-cycle fatigue degradation.

To this end, these available models have not been validated in fibre-based models. The initial work conducted by Kashani et al. (2015a,b) resulted in development of a uniaxial material model for reinforcing bars that accounts for inelastic buckling and low-cycle fatigue degradation. This current paper extends the previous work and implement this comprehensive material constitutive model within an advance fibre-based finite element model. The proposed modelling technique addresses the issue related to simulating the nonlinear flexural response of rectangular RC components (beams and columns) in building structures that fail due to inelastic buckling and/or low-cycle fatigue degradation of reinforcing bars. This model employs a nonlinear fibre beam-column element. The proposed uniaxial material model is developed using the experimental and numerical analysis data of isolated bars outside of concrete (Kashani 2014). Therefore, a comprehensive parametric study needs to be conducted to calibrate this material model to account for the influence of horizontal tie reinforcement (also known as confining reinforcement) on cyclic response of buckled reinforcing bars inside RC columns. It should be noted that in this approach, only one material model need be calibrated. Once the material model is calibrated it doesn't need any further calibration and can be used in any analysis. Through the parametric study the cyclic degradation of hysteretic loops of the uniaxial material model of reinforcing bars is calibrated against an extensive experimental dataset of 22 rectangular RC columns. This new modelling technique is able to predict the nonlinear behaviour of RC columns accounting for the influence of inelastic buckling and low-cycle fatigue degradation. It can accurately capture the multiple failure modes of RC components simultaneously and thereby significantly improves the accuracy of structural response simulation due to severe earthquake ground motions. This is demonstrated by implementing the model in a typical RC frame to show the influence of incorporating more complex failure mechanisms on the collapse assessment of the structure. The other significant contribution of this study is to evaluate the progression of the low-cycle fatigue damage and consumption of fatigue life of RC components. This is extremely important for postearthquake damage assessment of structures. For instance, if a structure is subjected to a sequence of earthquake events, it is possible to estimate the extent of damage after an earthquake and subsequently the economic loss. Therefore, the proposed research in paper has a significant impact in both industry 
and society. It can also support the insurance companies responsible in insuring buildings after large earthquake events for reliable estimation of the residual capacity of damaged RC structures after large earthquake sequence.

\section{Experimental data}

The University of Washington-Pacific Earthquake Engineering Research Centre (UW-PEER) RC column test database (Berry et al. 2004) provides an opportunity to study and optimise the model parameters of axially loaded RC components. The database documents the geometry, material properties, and reinforcement details of the columns. It also includes the force-displacement data, and the observed displacements at the onset of multiple damage states. In this study, 22 experiments where column buckling played a critical role are considered for model calibration and validation. Table 1 summarises the details of the selected columns and their references. In Table 1, $L$ is the column length, $L / D$ is the ratio of column length to column diameter, $\rho_{l}$ is the ratio of longitudinal reinforcement area to total cross sectional area, $\rho_{h}$ is the volumetric ratio of horizontal reinforcement, and $P /\left(A_{g} f_{c}\right)$ is the axial force ratio, where $P$ is the axial force applied to the column, $A_{g}$ is the gross cross sectional area of column, and $f_{c}$ is the compressive strength of concrete. The details of material properties can be found in the UW-PEER column database and in the relevant reference that is shown in Table 1. It should be noted that the experimental tests include a series of cantilever and double-ended column tests that are identified in Table 1 and illustrated in Fig. 1.

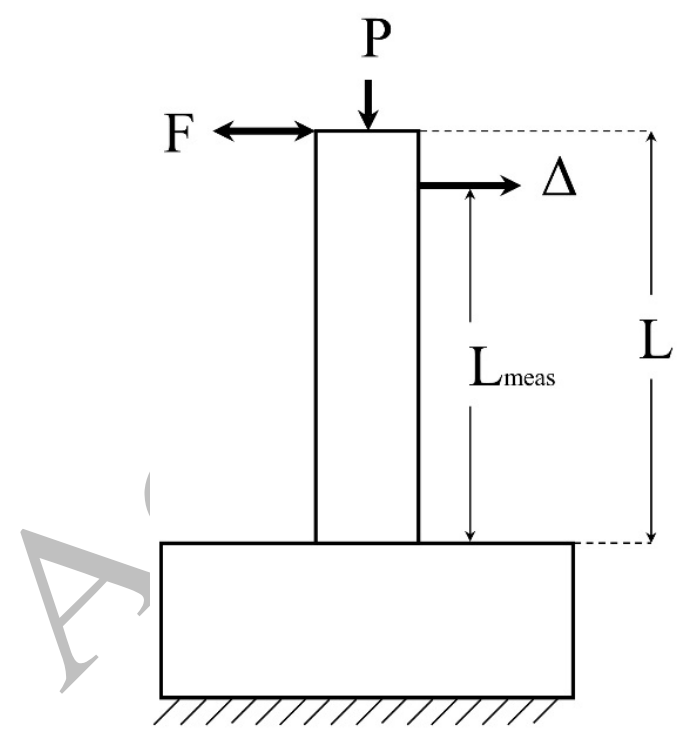

a) Cantilever

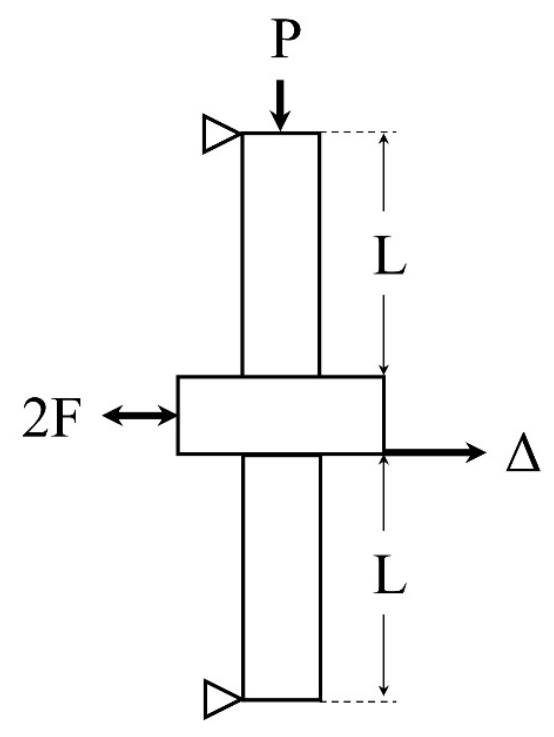

b) Double - Ended

Fig. 1 Column test configuration: (a) Cantilever and (b) Double-Ended

To account for the $P$ - $\triangle$ effects, the column forces provided in the database are resolved into vertical and horizontal components. The vertical component can be approximated by $P$ (i.e. axial load indicated in the database). The horizontal component of the vertical actuator needs to be added to (or 
subtracted from) the force applied by the horizontal actuator to obtain the net horizontal force. The experimental tests that are used in this research can be classified into three cases as shown in Fig. 2 and are indicated in Table 1. The database manual provides simplified equations for correcting the horizontal actuator force to account for the $P-\Delta$ effects. Further discussion and $P-\triangle$ correction equations are available in (Berry et al. 2004).

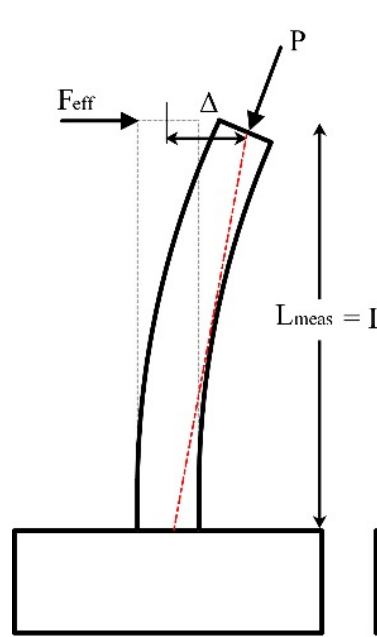

a) Case I

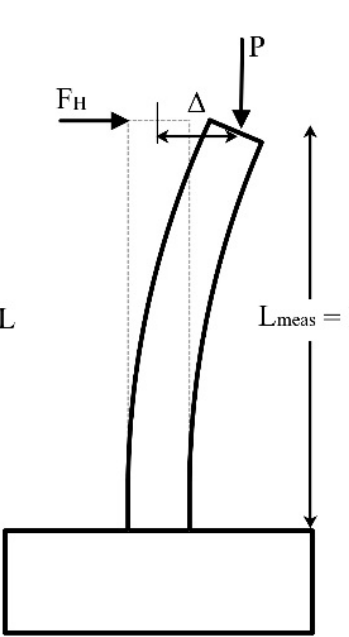

b) Case II

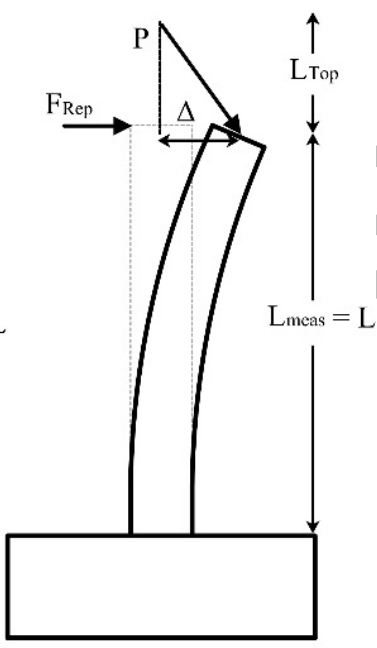

c) Case III

Fig. $2 P$ - $\Delta$ cases reported in the UW-PEER database manual

Table 1 Experimental column dataset

\begin{tabular}{|c|c|c|c|c|c|c|c|c|}
\hline ID & Reference & $\begin{array}{c}\text { Test } \\
\text { Type }\end{array}$ & $\begin{array}{c}\text { Span } \\
\text { to } \\
\text { Depth } \\
\text { ratio }\end{array}$ & $\begin{array}{c}\text { Concrete } \\
\text { Strength } \\
\text { (MPa) }\end{array}$ & $\begin{array}{c}\text { Vertical } \\
\text { Reinforcement } \\
\text { Ratio, } \rho_{l}\end{array}$ & $\begin{array}{c}\text { Horizontal } \\
\text { Reinforcement, } \\
\text { Ratio } \rho_{h}\end{array}$ & $\begin{array}{c}\text { Axial } \\
\text { Force } \\
\text { ratio, } \\
P /\left(A_{g} f_{c}\right) \\
\end{array}$ & $\begin{array}{c}\mathrm{P}-\Delta \\
\text { cases }\end{array}$ \\
\hline 1 & Ang et al., No. 3 (1981) & $\mathrm{DE}$ & 4.00 & 23.6 & 0.0151 & 0.028 & 0.38 & II \\
\hline 2 & Ang et al., No. 4 (1981) & $\mathrm{DE}$ & 4.00 & 25.0 & 0.0151 & 0.022 & 0.21 & II \\
\hline 3 & Soesianawati et al., No. 1 (1986) & $\mathrm{DE}$ & 4.00 & 46.5 & 0.0151 & 0.009 & 0.10 & II \\
\hline 4 & Soesianawati et al., No. 2 (1986) & $\mathrm{DE}$ & 4.00 & 44.0 & 0.0151 & 0.012 & 0.30 & II \\
\hline 5 & Soesianawati et al., No. 3 (1986) & $\mathrm{DE}$ & 4.00 & 44.0 & 0.0151 & 0.008 & 0.30 & II \\
\hline 6 & Soesianawati et al., No. 4 (1986) & $\mathrm{DE}$ & 4.00 & 40.0 & 0.0151 & 0.006 & 0.30 & II \\
\hline 7 & Zahn et al., No. 7 (1986) & $\mathrm{DE}$ & 4.00 & 28.3 & 0.0151 & 0.016 & 0.22 & II \\
\hline 8 & Zahn et al., No. 8 (1986) & $\mathrm{DE}$ & 4.00 & 40.1 & 0.0151 & 0.02 & 0.39 & II \\
\hline 9 & Tanaka and Park, No. 1 (1990) & $\mathrm{DE}$ & 4.00 & 25.6 & 0.0157 & 0.025 & 0.20 & II \\
\hline 10 & Tanaka and Park, No. 2 (1990) & $\mathrm{DE}$ & 4.00 & 25.6 & 0.0157 & 0.025 & 0.20 & II \\
\hline 11 & Tanaka and Park, No. 3 (1990) & $\mathrm{DE}$ & 4.00 & 25.6 & 0.0157 & 0.025 & 0.20 & II \\
\hline 12 & Tanaka and Park, No. 4 (1990) & $\mathrm{DE}$ & 4.00 & 25.6 & 0.0157 & 0.025 & 0.20 & II \\
\hline 13 & Tanaka and Park, No. 5 (1990) & $\mathrm{C}$ & 3.00 & 32.0 & 0.0125 & 0.017 & 0.10 & II \\
\hline 14 & Tanaka and Park, No. 6 (1990) & $\mathrm{C}$ & 3.00 & 32.0 & 0.0125 & 0.017 & 0.10 & II \\
\hline 15 & Park and Paulay, No. 9 (1990) & $\mathrm{C}$ & 2.97 & 26.9 & 0.0188 & 0.022 & 0.10 & II \\
\hline 16 & $\begin{array}{l}\text { Atalay and Penzien, No. 6S1 } \\
(1975)\end{array}$ & $\mathrm{DE}$ & 5.50 & 31.8 & 0.0163 & 0.009 & 0.18 & II \\
\hline
\end{tabular}




\begin{tabular}{lllllllll}
\hline 17 & Wehbe et al., A1 (1998) & C & 3.83 & 27.2 & 0.0222 & 0.004 & 0.10 & I \\
\hline 18 & Wehbe et al., A2 (1998) & C & 3.83 & 27.2 & 0.0222 & 0.004 & 0.24 & I \\
\hline 19 & Wehbe et al., B1 (1998) & $\mathrm{C}$ & 3.83 & 28.1 & 0.0222 & 0.005 & 0.09 & I \\
\hline 20 & Saatcioglu and Grira, BG-4 (1999) & $\mathrm{C}$ & 4.70 & 34.0 & 0.0293 & 0.013 & 0.46 & III \\
\hline 21 & Saatcioglu and Grira, BG-5 (1999) & $\mathrm{C}$ & 4.70 & 34.0 & 0.0293 & 0.027 & 0.46 & III \\
\hline 22 & Saatcioglu and Grira, BG-8 (1999) & $\mathrm{C}$ & 4.70 & 34.0 & 0.0293 & 0.013 & 0.23 & III \\
\hline & Mean & & 4.00 & 31.87 & 0.018 & 0.016 & 0.23 & NA \\
\hline & Standard Deviation & 0.56 & 6.82 & 0.005 & 0.008 & 0.11 & NA \\
\hline$\quad$ Max & & 5.50 & 46.50 & 0.029 & 0.028 & 0.46 & NA \\
\hline$\quad$ Min & & 2.97 & 23.60 & 0.013 & 0.004 & 0.09 & NA \\
\hline
\end{tabular}

C: Cantilever, DE: Double-Ended as shown in Fig. 1

\section{Finite element model of rectangular $\mathrm{RC}$ columns}

There are two FE formulations to model the nonlinear flexural response of beams and columns using the distributed-plasticity technique (Taucer et al. 1991; Spacone et al. 1996a, b). These methods are known as displacement-based and force-based formulations. In the displacement-based formulation, the displacement fields along the element are expressed as a function of/nodal displacements. The assumed displacement fields are approximations of the actual displacement fields and therefore, several elements per member are required to obtain a good approximation of the exact response. In the force-based formulation, the internal force fields are expressed as a function of nodal forces. Force-based elements are the most common type of the element formulations that are currently used in nonlinear analysis of framed structures. This is because they allow for the spread of plasticity over the length of the element using only one element with multiple integration points. In this research, the forced-based formulation is adopted.

To model the material nonlinearity within the element, the fibre section technique is used. The fibre section is a method that approximates the cross section of column using a number of steel and concrete fibres at selected locations along the element (known as integration points). The nonlinear section response is then captured by moment-curvature response of the fibre sections. In the force-based formulation, a moment-distribution along the length of the column is considered. The curvatures at each integration point are subsequently estimated for the given moment at that section. Finally, the column response is obtained by weighting the sectional responses at the integration points. Therefore, selection of the location of integration points is crucial for realistic prediction of the nonlinear response. In RC beams and columns, inelastic behaviour usually occurs near the ends of the component (i.e. plastic hinge region). Therefore, a Gauss-Lobatto integration scheme, in which the integration points are placed at the ends of the element as well as along the column length, is suitable (OpenSees 2011). 
It is noteworthy to mention that softening type behaviour structural component, results in strain localisation at the critical section in the forced-based elements. This will result in inaccurate prediction of the response at local and/or global level (Coleman and Spacone 2001; Pugh 2012). Coleman and Spacone (2001) proposed a simple material regularisation technique to solve this problem. The proposed material regularisation technique is based on the observed failure mode of concrete cylinder in compression tests. Pugh (2012) successfully applied this method to predict the nonlinear cyclic response of RC shear walls using force-based fibre beam-column elements. Using this concept the constitutive material model needs to be modified based on the integration length for the critical section to avoid the localisation problem.

In this research, a different method is employed to avoid the strain localisation due to the postbuckling response of reinforcing bars. This method has successfully been used by Kashani et al. (2016) in modelling nonlinear behaviour of circular columns. In this method, the whole column is modelled using two elements (Fig.3) and the integration length of the first section of the first element is set equal to the buckling length. With this approach, the dissipated energy under the post-buckling response of the material model for reinforcing steel remains unchanged. Kashani et al. (2016) reported that if the total length of the first element sets to $6 L_{\text {eff }}$ where $L_{\text {eff }}$ is the buckling length $\left(L_{\text {eff }}\right.$ is defined in Section 4 of this paper), the length of the integration point at the end of the element is equal to $L_{\text {eff }}$. Using this method, the length of the first element at the bottom of the column is adjusted based on the buckling length for each column. Based on the recommendations suggested by Berry and Eberhard (2006) a forced-based element with five integration points is considered for modelling the top part of the column. The numbers of fibres and the section and decomposition method are based on the recommendations given by Berry and Eberhard (2006). To model the strain penetration and the slippage of reinforcement anchored to the foundation, a zero-length section element available in the OpenSees (OpenSees 2011; Kashani 2014) is used. The detailed discussion of the zero-length section is given in Section 5.3 of this paper. 


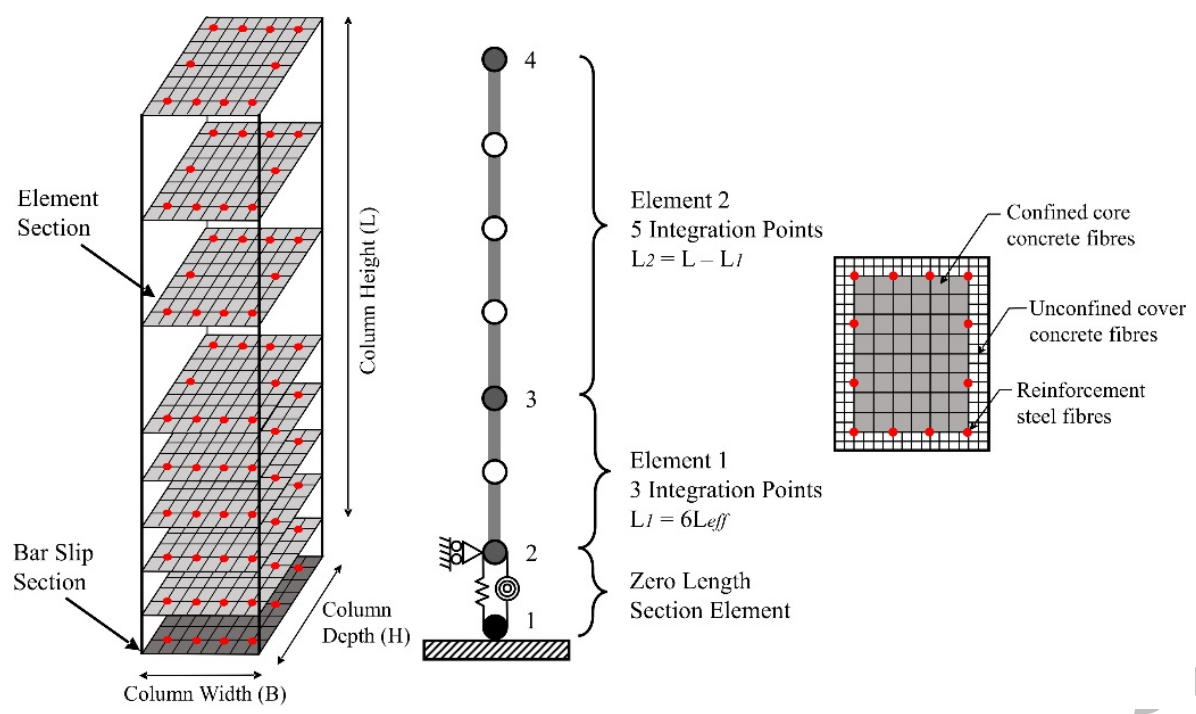

Fig. 3 Proposed finite element model using forced-base nonlinear fibre beam-column element

A displacement control with an adaptive solution algorithm is developed using the $T c l$ code in the OpenSees to run the nonlinear analysis. To ensure the numerical convergence of the solution, the norm of displacement increment is checked against a defined tolerance. This command is implemented in the OpenSees to conduct a convergence test which uses the norm of the solution error vector of the matrix equation to determine if convergence has been reached. The tolerance is set to $10^{-4}$ over the maximum of 35 iterations. The analysis starts with a Newton-Raphson solution algorithm. When the convergence is not achieved, the displacement increment is cut by a factor of 0.1 and this is repeated twice. In case where the convergence is not achieved by cutting the step sizes twice, different solution algorithms are trialled. The solution algorithms used in the adaptive solution strategy include: Newton-Raphson, modified Newton-Raphson, Newton-Raphson with Line Search and Krylov-Newton algorithms. Further details of the algorithm commands are available in OpenSees (2011). These algorithms were very effective in obtaining accurate and robust results in nonlinear analyses.

\section{Calculation of buckling length of vertical reinforcement in rectangular columns}

Dhakal and Maekawa (2005b) studied the buckling behaviour of vertical reinforcement in rectangular columns. Using an energy method, they derived the buckling mode shape accounting for the influence of tie stiffness on buckling length. This model was used in FE analysis of a cantilever column that was subjected to lateral and axial loads. The results of this model agreed fairly well with experimental results. In the Dhakal-Maekawa model, the vertical reinforcing bar is considered as a beam fixed at both ends of the buckling length to emulate the restraining mechanism of horizontal ties. A cosine shape function satisfying the fixed boundary condition is then employed to define the deformed configuration of the buckled bar. As the buckling of reinforcing bars is an inelastic buckling phenomenon, the elastic flexural rigidity $E_{S} I$ cannot be used. Dhakal and Maekawa (2005b) suggested 
an average flexural rigidity $E I$, defined in Eq. (1), which has been validated against an extensive set of experimental data.

$$
E I=\frac{E_{s} I}{4} \sqrt{\frac{\sigma_{y}}{100}}
$$

where $I, E_{s}$ and $\sigma_{y}$ are the second moment of area, elastic modules and yield strength of the vertical reinforcement in $\mathrm{mm}^{4}$ and $\mathrm{MPa}$, respectively. Further discussion about the development and implementation of this model is available in (Dhakal and Maekawa 2005b; Kashani 2014). The calculated buckling lengths together with reinforcement details of the column dataset are available in Table A1 of Appendix A.

\section{Uniaxial material models}

\subsection{Concrete model}

In this research, a material model developed by Park et al. (1982) is used. This model is known as Concrete02 in the OpenSees. It has a parabolic curve up to the maximum concrete stress and a linear post-peak softening branch afterward. The model also includes a linear tension stiffening. Further details of the model parameters, equations and implementation are available in the OpenSees (2011). Fig. 4 shows an example of cyclic response of this model for confined and unconfined concrete. In Fig. $4, \sigma$ is the concrete stress, the $\sigma_{c}$ is the maximum compressive stress of concrete, $\varepsilon$ is the concrete strain and $\varepsilon_{c 0}$ is the concrete strain at maximum compressive stress. In Fig. 4, the cyclic loops of confined concrete shown for values of psi up to -6 will continue until. They are not presented in the figure for clarity of Fig. 4. Further details about this model is available in Park et al. (1982).

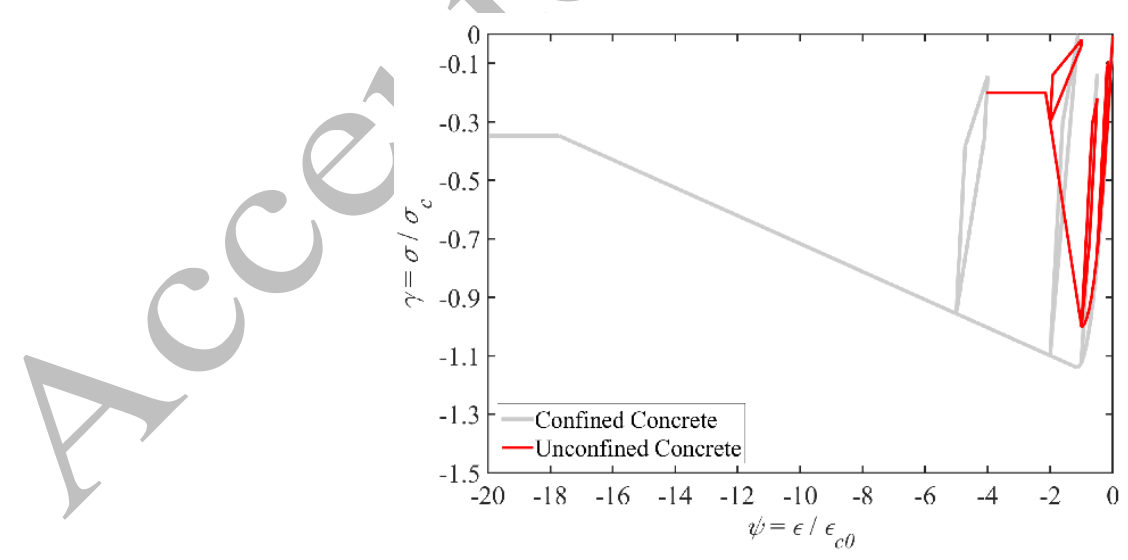

Fig. 4 Cyclic response of concrete uniaxial material model (Concrete02 in the OpenSees)

\subsection{Reinforcing steel model}

\subsubsection{Conventional uniaxial material model of reinforcing steel}

The cyclic response of this reinforcing steel material model is defined by the Giuffre-MenegottoPinto (1973) equations (GMP) which have been modified by Fllipou et al. (1983). This model is 
available in the OpenSees known as Steel02 uniaxial material model. The Steel02 accounts for the Bauschinger effect (Bauschinger 1887), but does not account for cyclic strength and stiffness degradation due to bar buckling and fatigue. An example cyclic response of the conventional steel model in the OpenSees is shown in Fig. 5. This model is used as benchmark to evaluate the influence of buckling and cyclic degradation on prediction of inelastic response of rectangular RC columns.

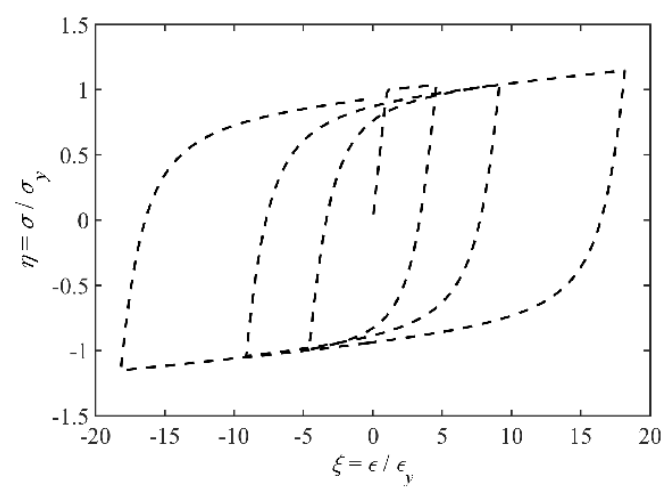

Fig. 5 Cyclic response of the conventional uniaxial material model of reinforcing steel (Steel02 in the OpenSees)

\subsubsection{Uniaxial material model including the effect of inelastic buckling}

Kashani et al. (2015a) developed a new phenomenological uniaxial material model for reinforcing bars. The new material model accounts for the influence of inelastic buckling and low-cycle fatigue degradation. The material parameters are calibrated based on experimental and numerical simulation data of isolated bars.

The basic tension envelope employs a continuous function that enables a smooth transition from the linear elastic to the strain hardening region. This improves the numerical stability during the computational process. Therefore, this model is used to define the tension envelope (Eq. (2)).

$\sigma=\sigma_{y} \frac{(1-\mu)}{2}\left[1+\frac{(1+\mu)}{(1-\mu)} \frac{\varepsilon}{\varepsilon_{y}}-\sqrt{\left(\frac{\varepsilon}{\varepsilon_{y}}\right)^{2}+\delta}\right]$

where $\mu=E_{h} / E_{s}$ is the hardening ratio with $E_{s}$ and $E_{h}$ equal to the elastic modulus and hardening modulus for the steel, $\sigma_{y}$ is the yield stress, $\varepsilon$ is the current strain, $\varepsilon_{y}$ is the yield strain, and $\delta$ is a shape parameter. Eq. (2) represents a hyperbola with two asymptotes, one with slope $E_{s}$ and the other with slope $E_{h}$. The shape parameter, $\delta$, defines the curvature radius of the transition between the linear elastic and hardening regions of the curve. Further details of this model are available in Kashani et al. (2015a).

The basic compression envelope of the model employs an exponential function to characterise the post-yield bucking response of the reinforcing bars. This is defined in Eq. (3): 
$\sigma=\left\{\begin{array}{l}E_{s} \varepsilon \\ \sigma^{*}+\left(\sigma_{y}-\sigma^{*}\right) \exp \left(-\left(\rho_{1}+\rho_{2} \sqrt{\varepsilon_{p}}\right)\left(\varepsilon_{p}\right)\right) \\ : \varepsilon>\varepsilon_{y}\end{array} \quad\right.$ for $8 \leq \frac{L_{e f f}}{d} \leq 30$

where $\rho_{1}$ is the initial tangent of the post-buckling response curve, $\rho_{2}$ is the rate of change of the tangent, $\varepsilon$ is the current strain, $\varepsilon_{p}=\varepsilon-\varepsilon_{y}$ is the plastic strain, $\sigma^{*}$ is the asymptotic lower stress limit of the post-buckling curve, and all other variables are as previously defined. The parameters $\rho_{1}, \rho_{2}$, and $\sigma^{*}$ are defined by the yield strength and the geometrical slenderness ratio of the reinforcing steel:

$\rho_{1}\left(\lambda_{p}\right)=4.572 \lambda_{p}-74.43$

$\rho_{2}\left(\lambda_{p}\right)=318.40 \exp \left(-0.071 \lambda_{p}\right)$

$\sigma^{*}=3.75 \frac{\sigma_{y}}{\frac{L_{e f f}}{d}}$

$\lambda_{p}=\sqrt{\frac{\sigma_{y}}{100}} \frac{L_{e f f}}{d}$

where $\sigma_{y}$ has units of MPa. Further discussion and detailed derivation of the above equations are available in Kashani et al. (2015a).

It should be noted that the preceding model is developed using the experimental data of isolated bars. To account for the influence of horizontal tie reinforcement, the model needs further calibration. Therefore, a generic Hysteretic model in the OpenSees is fitted to the above model for calibration of cyclic parameters to account for the effect of horizontal tie reinforcement (Fig. 6). Details of calibration process and parametric study are discussed in Section 6 of this paper.

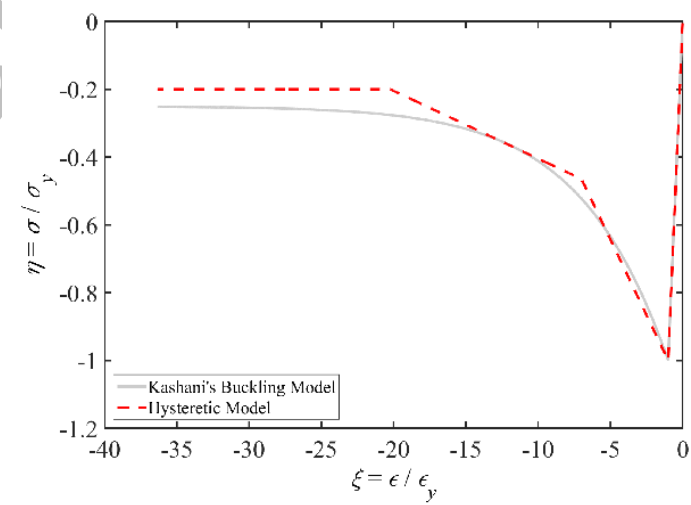

Fig. 6 Compression envelope of Hysteretic model fitted to the Kashani's model using trilinear curve

\subsection{Slip model for zero-length element}

In the seismic design of RC structures, plastic hinges are formed at the column/beam ends. This will induce a substantial strain penetration along the longitudinal bars into the joint that eventually results in slippage of the longitudinal bars. Lowes and Altoontash (2003) adopted a bar-slip model for the 
end slip of longitudinal reinforcement in beam-column joints. Berry and Eberhard (2006) provide recommendations on implementation of such slip models in the OpenSees. Based on their recommendation, the zero-length section element available in the OpenSees can be used to model the slippage of reinforcing bars. Accordingly, the uniaxial material models of steel and concrete in the zero-length section element should be modified. In this research, the model developed by Lowes and Altoontash (2003) with recommendations suggested by Berry and Eberhard (2006) is adopted. Further details of the model development and implementation of the model in the OpenSees are available in Berry and Eberhard (2006).

\subsection{Modelling material failure due to low-cycle fatigue degradation}

The OpenSees has a generic fatigue material model that can be wrapped to any steel model without changing the stress-strain state of the parent material. This material model accounts for the effect of low-cycle fatigue and is known as uniaxial Fatigue material model in the OpenSees (Uriz 2005). The cycle counter algorithm is used in conjunction with the Coffin-Manson relationship (Eq. (8)) and Miner's rule to describe the low-cycle fatigue failure (Manson 1965; Miner 1945).

$\varepsilon_{p}=\varepsilon_{f}\left(2 N_{f}\right)^{-\alpha}$

where $\varepsilon_{p}$ is the plastic strain amplitude $\left(\varepsilon_{p}=\varepsilon_{a}-\varepsilon_{e} ; \varepsilon_{a}\right.$ is the total strain amplitude and $\varepsilon_{e}$ is the elastic strain), $2 N_{f}$ is the number of half-cycles to failure and $\alpha$ and $\varepsilon_{f}$ are the material constants.

The material constants $\alpha$ and $\varepsilon_{f}$ are the input parameters in the Fatigue model. Once the Fatigue material reaches a damage state of 1.0 , the stress of the parent steel material becomes zero. An example graph of the Fatigue material model wrapped to Steel02 is shown in Fig. 7.

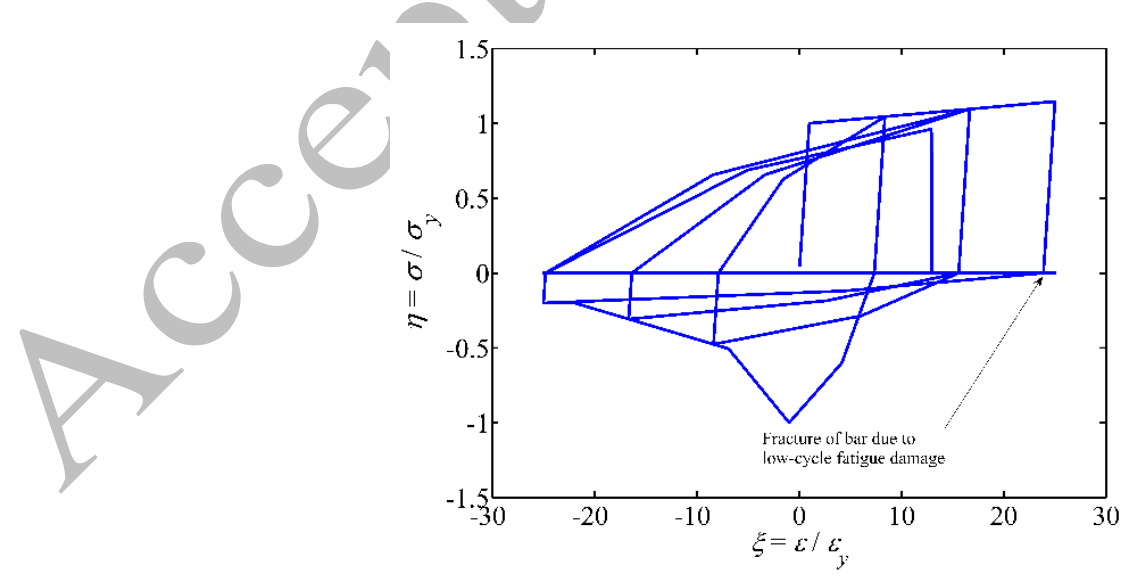

Fig. 7 Fatigue material model to predict the fracture of reinforcement due to low-cycle fatigue 


\section{Parametric study to calibrate model parameters}

\subsection{Pinching parameters}

In this section, different combinations of pinching parameters are considered to obtain suitable hysteretic model parameters using the experimental column dataset (Table 1). This is to account for the influence of horizontal tie reinforcement on the pinching response of the reinforcing bars due to inelastic buckling under cyclic loading. The pinching response in the Hysteretic material model in the OpenSees is defined by two pinching parameters, i.e. pinch $x$ and pinch $y$. The pinch $x$ and pinch $y$ range from 0 to 1 and control strain and stress, respectively. The pinch parameters used in this study are similar to the ones used by Kashani et al. (2016) for circular columns (Fig. 8). The considered combinations are summarised in Table 2. Further discussion about the pinching response in available in Kashani et al. (2016).

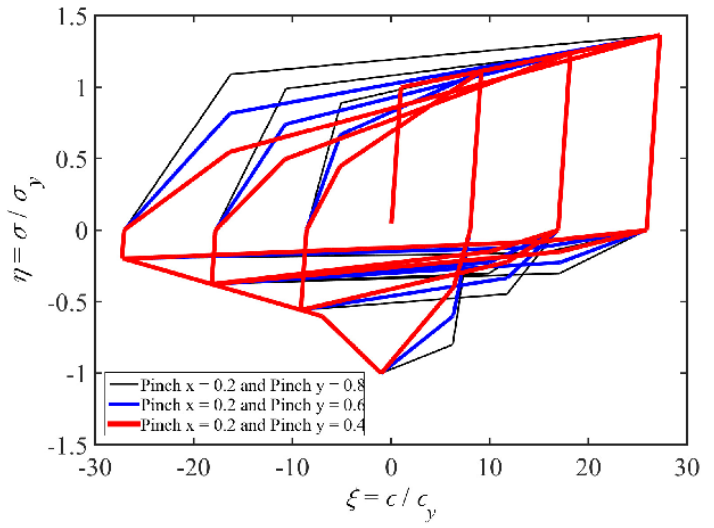

(a)

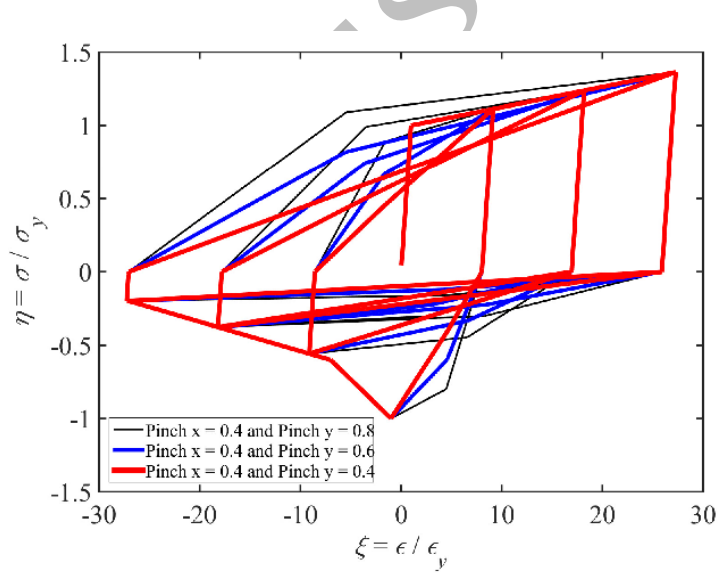

(b)

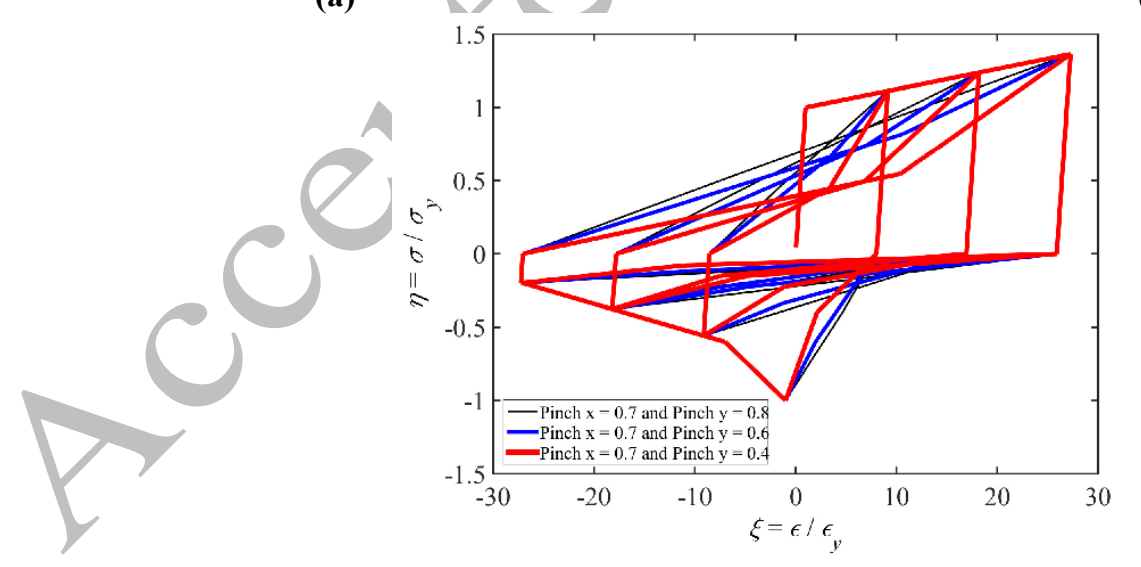

(c)

Fig. 8 Pinch combinations used in the parametric study: (a) combinations 1 to 3, small pinching (b) combinations 4 to 6 , moderate pinching and (c) combinations 7 to 9 , severe pinching

Table 2 Pinch combination used in the parametric study

\begin{tabular}{lccccccccc}
\hline Combination & $\mathbf{1}$ & $\mathbf{2}$ & $\mathbf{3}$ & $\mathbf{4}$ & $\mathbf{5}$ & $\mathbf{6}$ & $\mathbf{7}$ & $\mathbf{8}$ & $\mathbf{9}$ \\
\hline pinch $\boldsymbol{x}$ & 0.2 & 0.2 & 0.2 & 0.4 & 0.4 & 0.4 & 0.7 & 0.7 & 0.7 \\
\hline pinch $\boldsymbol{y}$ & 0.8 & 0.6 & 0.4 & 0.8 & 0.6 & 0.4 & 0.8 & 0.6 & 0.4 \\
\hline
\end{tabular}


Berry and Eberhard (2006) have successfully used the average energy error as a measure to calibrate the model parameters in nonlinear fibre element modelling of circular RC bridge piers. In this research, a similar method is used to measure the accuracy of the simulation results in the parametric study. The error ratio in hysteretic energy dissipation is defined in Eq. (9).

$$
\Omega_{E}=\frac{\left|E_{\text {experiment }}-E_{\text {model }}\right|}{\left|E_{\text {experiment }}\right|}
$$

In this study, the dissipated energy of the hysteretic cycles up to the maximum drift capacity is considered. The maximum drift capacity is determined as the drift at which point the column strength falls below $80 \%$ of the maximum column strength. It should be noted that the low-cycle fatigue is excluded from the parametric study. The influence of buckling of bars on fatigue material constants is investigated separately and is available in Kashani et al. (2015b).

Table 3 Statistical information of the error ratio $\left(\Omega_{\mathrm{E}}\right)$ in the parametric study

\subsection{Comparison of the hysteretic energy dissipation}

Fig. 9 shows the hysteretic energy dissipation error, $\Omega_{E}$, of each column test unit for all the pinch combinations. Table 3 shows the statistics of $\Omega_{E}$ for each pinch combination across the whole 22 column dataset. The mean errors in pinch combinations 5 to 9 are generally larger than others. The errors in combinations 1 and 3 are about $16 \%$ on average, whereas the errors in combinations 2 and 4 are around $13 \%$. Between combinations 2 and 4, it was found that the combination 2 has the smallest average error in predicted response.

The correlation between the pinching parameters and column properties $\left(\rho_{l}, s / d\right.$, etc.) is investigated. It is found that there is no significant correlation between these parameters. Therefore, the combination 2 is adopted as the suitable model for further analyses. Comparison of the results of this study and the results obtained by Kashani et al. (2014) for circular columns shows that the pinching response in circular columns is slightly more severe than rectangular columns. They reported that the pinching combination 5 is the optimal combination for circular columns.

\begin{tabular}{ccccccccccc}
\hline Combination & $\mathbf{1}$ & $\mathbf{2}$ & $\mathbf{3}$ & $\mathbf{4}$ & $\mathbf{5}$ & $\mathbf{6}$ & $\mathbf{7}$ & $\mathbf{8}$ & $\mathbf{9}$ & Steel02 \\
\hline Mean & 0.151 & 0.132 & 0.163 & 0.138 & 0.169 & 0.206 & 0.190 & 0.235 & 0.296 & 0.176 \\
\hline $\begin{array}{c}\text { Standard } \\
\text { Deviation }\end{array}$ & 0.142 & 0.119 & 0.087 & 0.118 & 0.085 & 0.085 & 0.077 & 0.104 & 0.129 & 0.172 \\
\hline Max & 0.571 & 0.428 & 0.370 & 0.422 & 0.371 & 0.421 & 0.381 & 0.440 & 0.512 & 0.630 \\
\hline Min & 0.008 & 0.002 & 0.005 & 0.001 & 0.004 & 0.054 & 0.047 & 0.008 & 0.050 & 0.003 \\
\hline
\end{tabular}

In general, what causes these differences is the results of cyclic degradation of material after inelastic buckling of vertical reinforcement. This behaviour can be affected by a number of factors such as 
axial force ratio, effective buckling length of vertical bars, confinement reinforcement, and ration of flexure rigidity of vertical bars and stiffness of tie reinforcement. Quantification of these parameters is a very complex problem and is an area for future research.

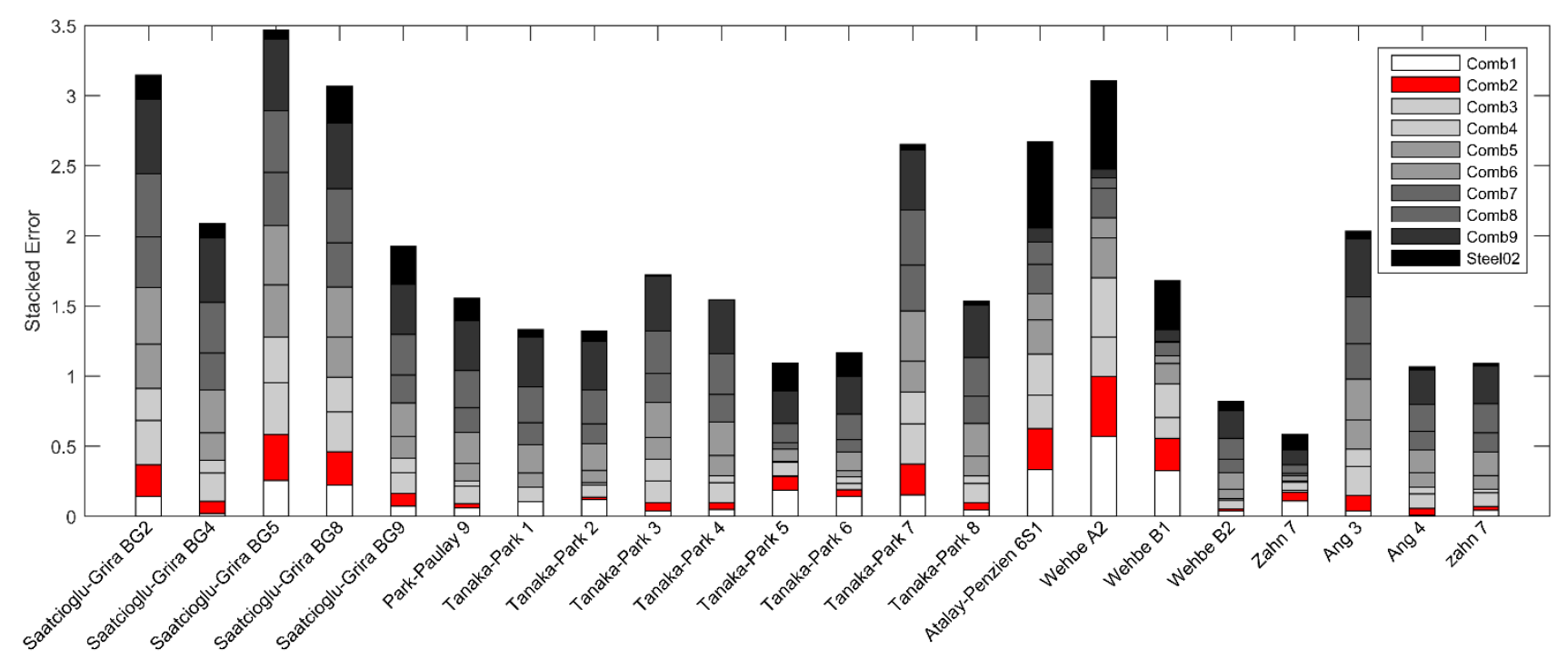

Fig. 9 Comparison of the hysteretic energy dissipation of pinch combinations

\section{Comparison and discussion of the results of buckling included model with experimental data}

To validate the basic FE model, preliminary analyses are conducted using the conventional Steel02 element without any buckling and degradation effect. A graphical comparison between the two examples of computed and observed experimental results is shown in Fig. 10. Fig. 10 shows that the FE model using Steel02 can accurately simulate the nonlinear column response and strength before the column starts to lose strength due to cyclic loading. However, once the column starts to degrade under cyclic load, the Steel02 cannot simulate this response. There are two main reasons for the differences between these responses. Firstly, the spacing of tie reinforcement $(s / d)$ has influence on the crushing of confined concrete as well as buckling of vertical reinforcement. Secondly, the axial force ratio applied to the column is relatively large. Because the response of the Steel02 material model doesn't include the inelastic buckling, the change of buckling length and axial force ratio cannot be captured in the simulation. Table A1 in Appendix A shows a summary of the calculated buckling lengths, axial force ratio, and other relevant information about the experimental results. 


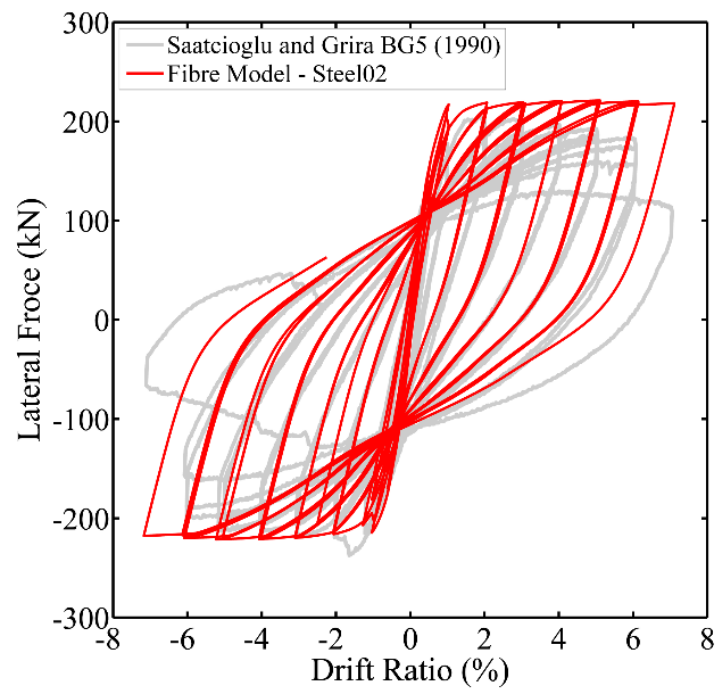

(a)

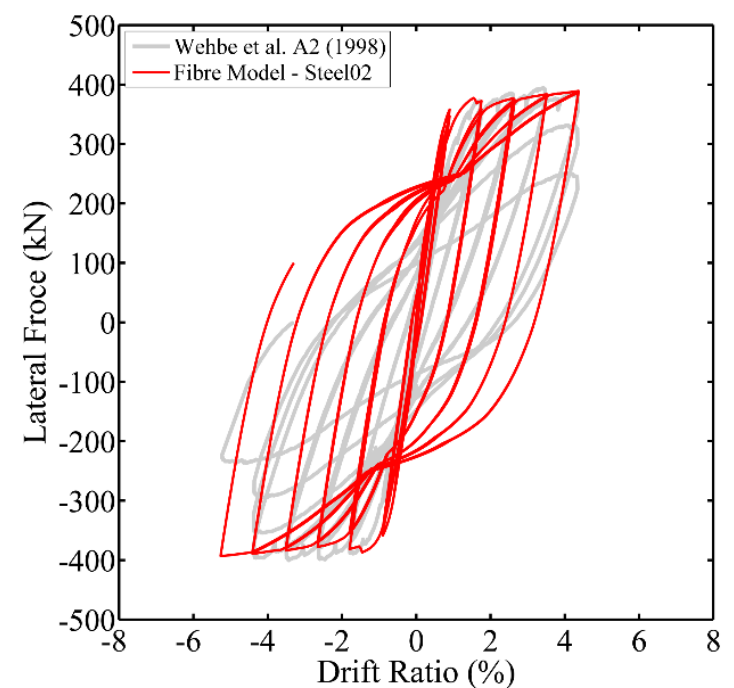

(b)

Fig. 10 Examples of computed force-displacement responses of the RC columns using Steel02 material model

A graphical comparison of the computed response of the OpenSees fibre model using the optimised uniaxial material model and the experimental data is shown in Fig. 11. Fig. 11 indicates that the computed results of the optimised model are in a good agreement with the results observed in the experimental tests. For example, consider Fig. 11(a) and (b) which show the Wehbe's columns A2 and B1. All the details of these two columns are identical apart from the axial force ratio and $s / d$. The column A2 has an axial force ratio of 0.24 and $s / d=5.85$, whereas the column B1 has an axial force ratio of 0.09 and $s / d=4.35$. The difference in $s / d$ results in a change in the buckling mode but the overall buckling length remained similar. The computed $L_{e f f} / d$ ratio of the test units A2 and B1 are 11.5 and 17.4, respectively. Although the spacing of horizontal tie reinforcement is closer in column $\mathrm{B} 1$, the stiffness of ties is not sufficient to restrain the bars against buckling. Furthermore, given the axial force applied to A2 is almost 2.5 times of the axial force applied to B1, the column A2 crushes much quicker.

Comparing the computed results of these columns using the fibre model with Steel02 and the optimised buckling material model shows that this behaviour cannot be captured in the fibre model with Steel02 (Fig. 10 and Fig. 11). This is because the buckling of vertical reinforcement results in softening of stress-strain behaviour of reinforcement in the post-buckling region. This increases the compressive stress of core confined concrete. As the compressive stress of core concrete increases, the combined effect of core expansion and the out of plane deformation of vertical bars due to buckling results in the fracture of horizontal tie reinforcement. Therefore, the core confined concrete crushes much quicker than a case where buckling of vertical reinforcement is not an issue. This mechanism results in a severe strength loss and cyclic degradation of the column which is clearly shown in Fig. 11(a-d). 
Fig 11(e-f) shows two cases with $L_{\text {eff }} / d<10$. Comparison of the results shows that the computed response using the model with Stee02 is very similar to the model with buckling. This is because that the softening response of the buckled bars with $L_{\text {eff }} / d<10$ is not very steep. As a result the core concrete does not crush quickly after buckling.

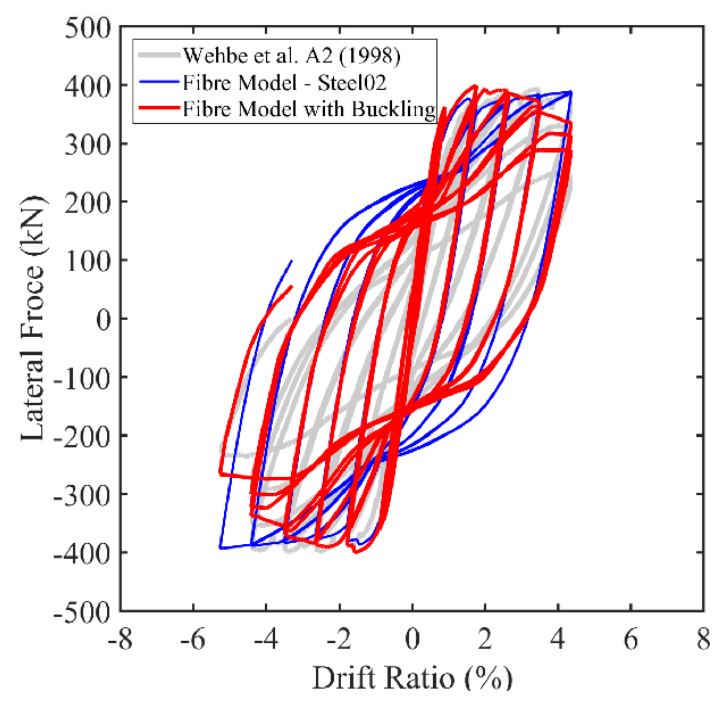

(a)

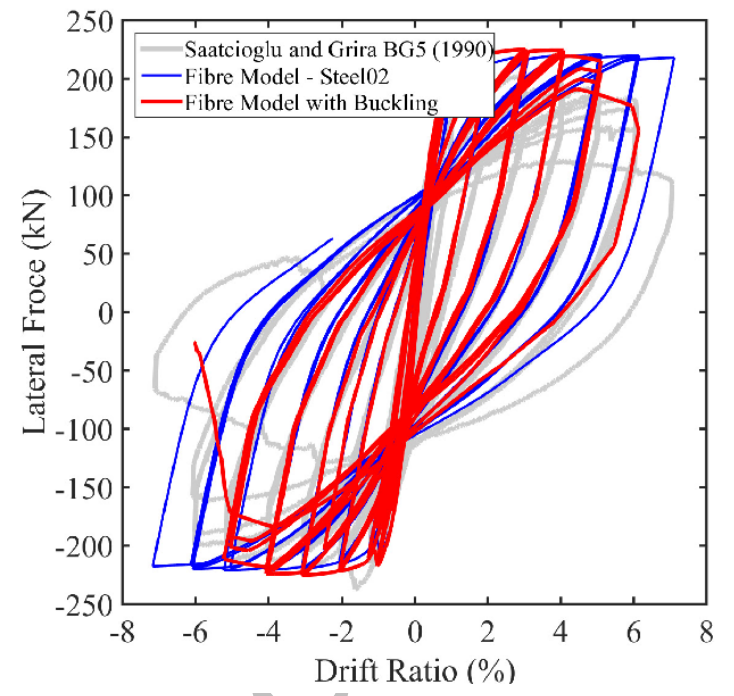

(c)

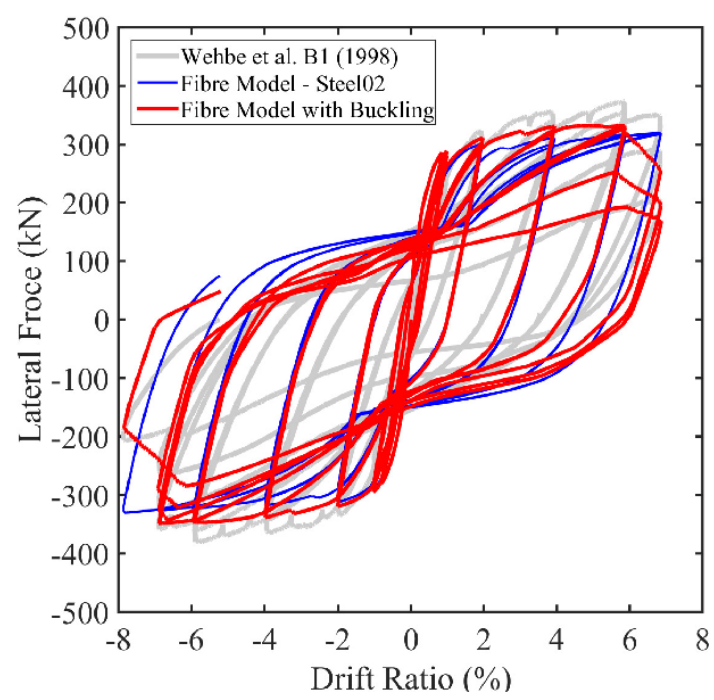

(b)

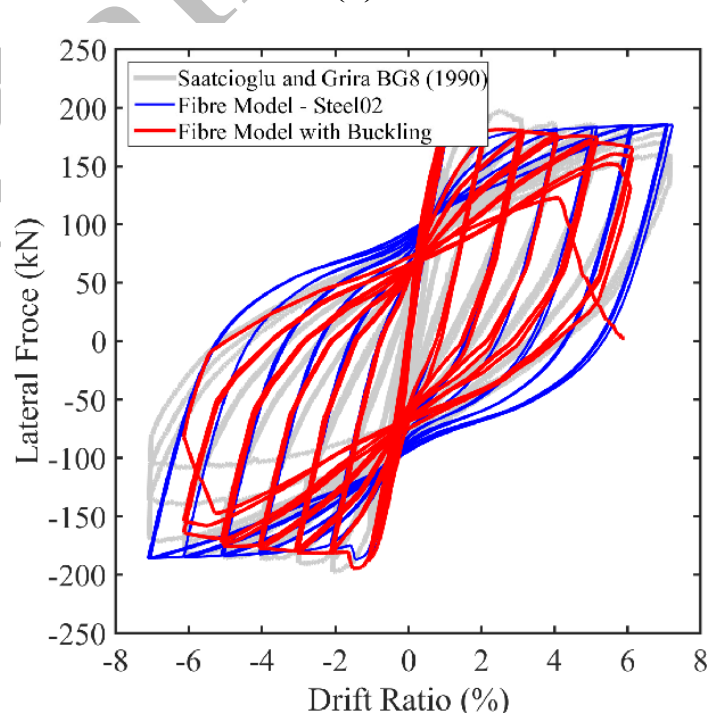

(d) 


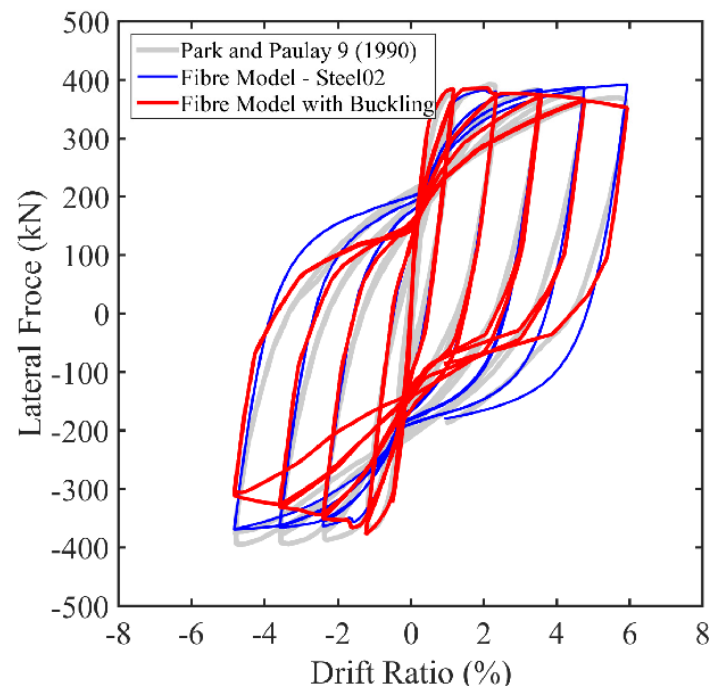

(e)

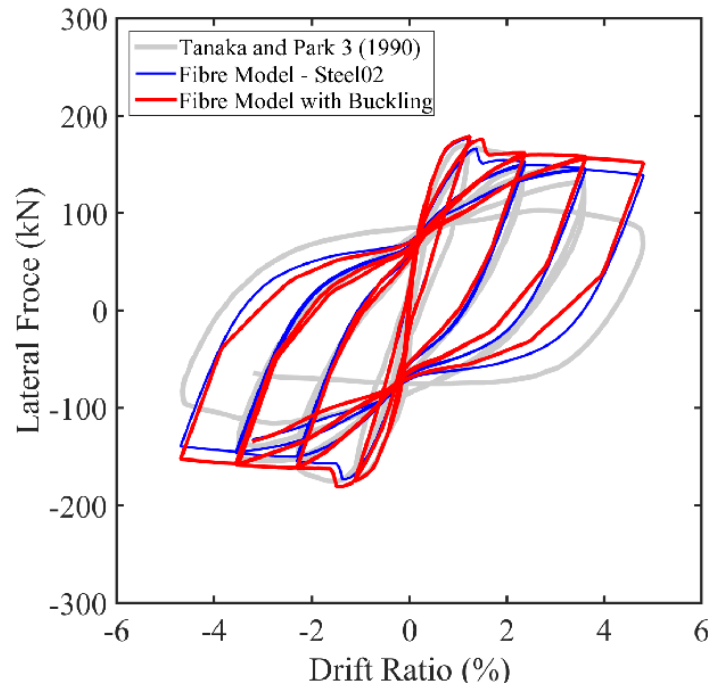

(f)

Fig. 11 Comparison of computed response of calibrated fibre using optimum buckling material model and experimental results

For quantitative comparison of the computational model with experimental results, the error in computed initial stiffness $\left(K_{\text {initial }}\right)$, strength at $1 \% \operatorname{drift}\left(F_{1}\right)$ and the strength at maximum $\operatorname{drift}\left(F_{\max }\right)$ are considered (Eq. (10)). The initial stiffness, $K_{\text {initial }}$, is defined as $F_{y} / \Delta_{y}$ where the $F_{y}$ is the force at first yield of reinforcement and $\Delta_{y}$ is the corresponding displacement, and the maximum drift capacity, $F_{\max }$, is the force at the maximum drift that column experienced during the physical test. Table A2 in Appendix A shows the results of this comparison including the statistics of the error metrics.

$\Psi_{\eta}=\left|\frac{\eta_{\text {experiment }}-\eta_{\text {computed }}}{\eta_{\text {experiment }}}\right|$

where $\eta_{\text {experiment }}$ is the experimental value of the considered variable $\left(K_{\text {initial }}, F_{1}\right.$, and $\left.F_{\text {max }}\right)$ and $\eta_{\text {computed }}$ is the computed predicted value of the considered variable $\left(K_{\text {initial }}, F_{1}\right.$, and $\left.F_{\text {max }}\right)$.

To show the influence of combined inelastic buckling and low-cycle fatigue degradation, the fatigue damage is evaluated for all the columns. Fig. 12 shows the accumulated fatigue damage of the four of the columns shown in Fig. 11. 


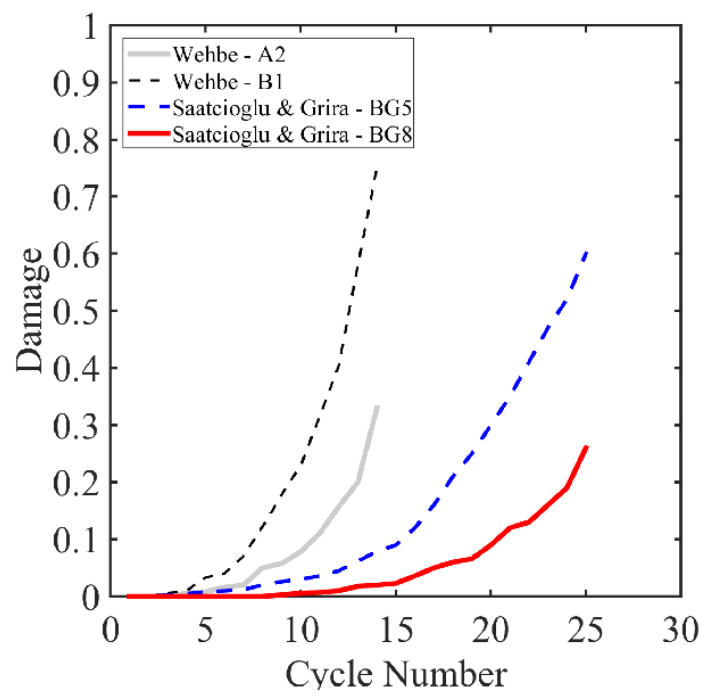

Fig. 12 Comparison of computed response of calibrated fibre using optimum buckling material model and experimental results

It is clear from Fig. 12 that Wehbe's column B1 and Saatcioglu's column BG5 have experienced more fatigue damage compared to Wehbe's column A2 and Saatcioglu's column BG8. This is in a good agreement with the experimental findings reported in Wehbe et al. (1998) and Saatcioglu and Grira (1999). As mentioned before, the $L_{\text {eff }} d$ ratios of vertical reinforcement in Whebe's columns A2 and B1 are 11.5 and 17.4, respectively, whereas those in Saatcioglu BG5 and BG8 are 7.8 and 11.7, respectively. The extremely high axial force ratio $(0.46)$ in Sattcioglu's column BG5 resulted in rapid fatigue damage despite the short $L_{\text {eff }} / d$ /ratio. However, it is clear that sever buckling of vertical reinforcement in Wehbe's column B1 resulted in more severe damage and degradation compared to Saatcioglu's columns despite having a very low axial force ratio (0.09). This is also in a good agreement with the experimental results of low-cycle fatigue tests of reinforcing bars with the effect of inelastic buckling [44]. Therefore, it is evident from Fig. 12 that the fatigue and cyclic degradation should be considered in nonlinear seismic analysis of RC structures.

\section{Application of the proposed model in nonlinear dynamic analysis of RC framed structures}

To show the significance of the issues related to fibre-based material modelling of bar buckling and fatigue degradation in nonlinear dynamic analysis of RC structures, an example is set up. The RC structure is a single storey frame that originally analysed by Haselton et al. (2011). The details of the proposed hypothetical RC frame are shown in Fig. 13. The vibration period of this structure is 0.32 S. 


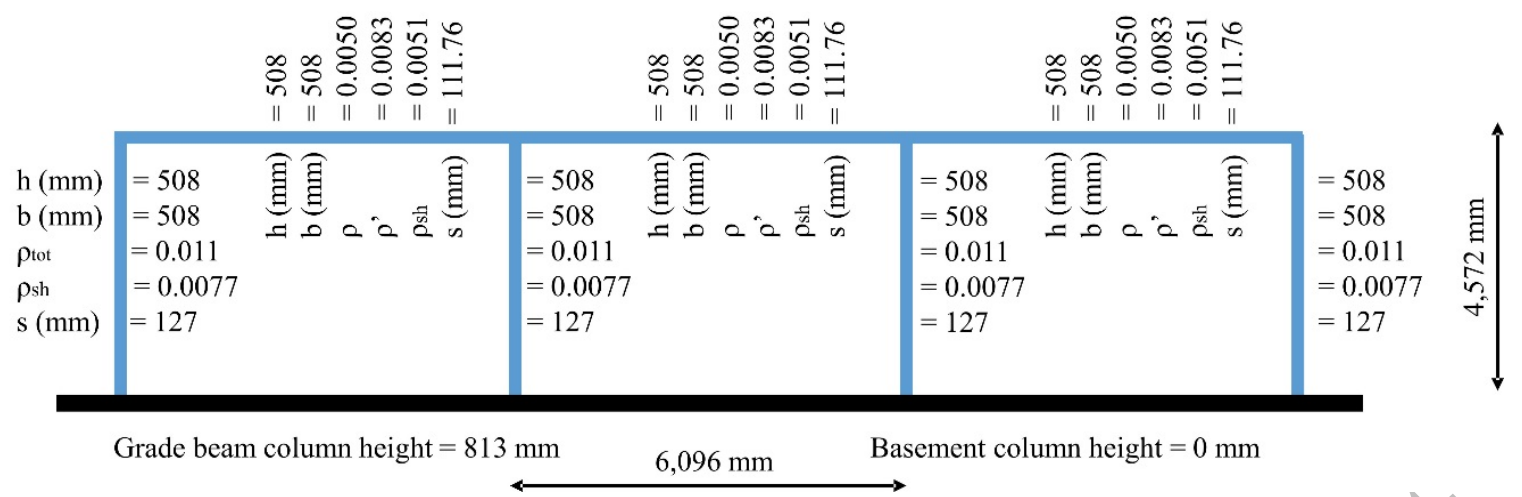

(a)
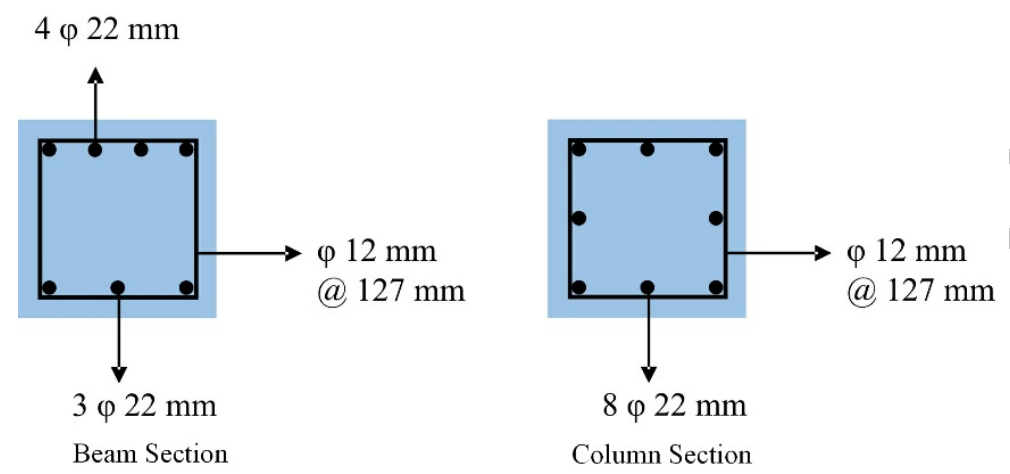

(b)

Fig. 13 Details of the hypothetical RC frame: (a) elevation view of the 2D frame and (b) cross section details of beams and columns

A static pushover analysis of the RC frame is conducted and the results of the models with and without accounting for buckling of longitudinal reinforcement are compared. Fig. 14 shows that the model without accounting for buckling of longitudinal reinforcement is not able to model the strength loss of the structure due to combined buckling and concrete crushing beyond about $3 \%$ drift. The model including the effect of buckling shows about $10 \%$ strength loss at 0.05 drift ratio, but the model without considering buckling effect shows a plateau. This is due to premature crushing of core concrete after buckling of vertical reinforcement. This behaviour cannot be captured without including the buckling effect in the model. This is more critical in nonlinear time-history analysis where the low-cycle fatigue of longitudinal reinforcement is also very important. 


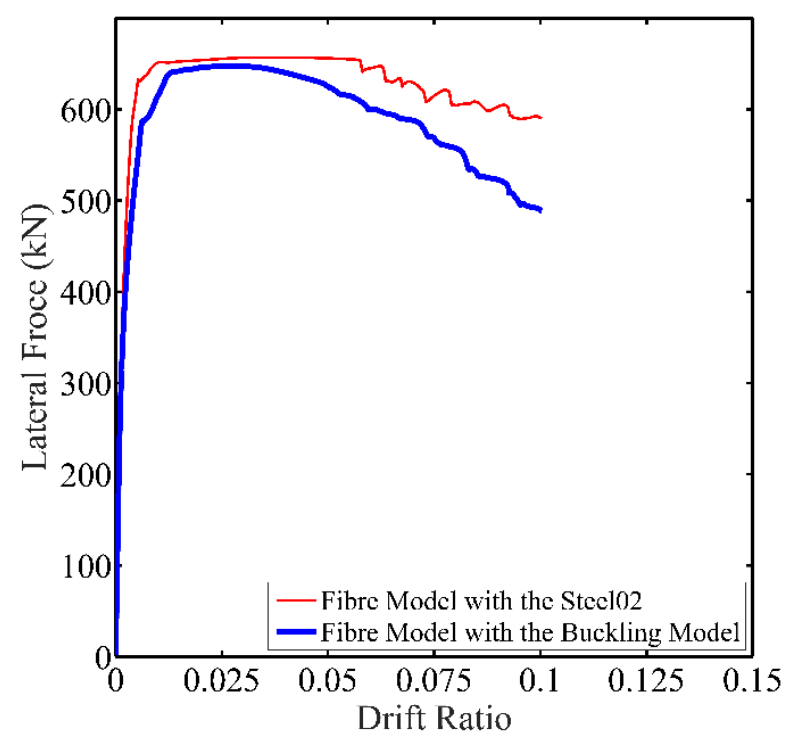

Fig. 14 Comparison of the nonlinear pushover analysis of the RC frame using the lumped-plasticity approach reported in Haselton et al. (2011) and the proposed model developed in this paper

One of the most popular methods for collapse assessment of RC structures is incremental dynamic analysis (IDA) (Vamvatsikos and Cornell 2002). In this method, the performance of a structure under a wide range of intensity measures (IMs) can be investigated. Therefore, IDA is performed on the example frame using two different material models subject to an earthquake ground motion from the 1995 Kobe earthquake, recorded at Shin-Osaka. The first model uses the conventional nonlinear fibre beam-column model without buckling and degradation effect; whereas the second model uses the new fibre beam-column model that accounts for inelastic buckling and low-cycle fatigue degradation of reinforcing bars. The time-history and the response spectrum of the input ground motion is shown in Fig. 15.
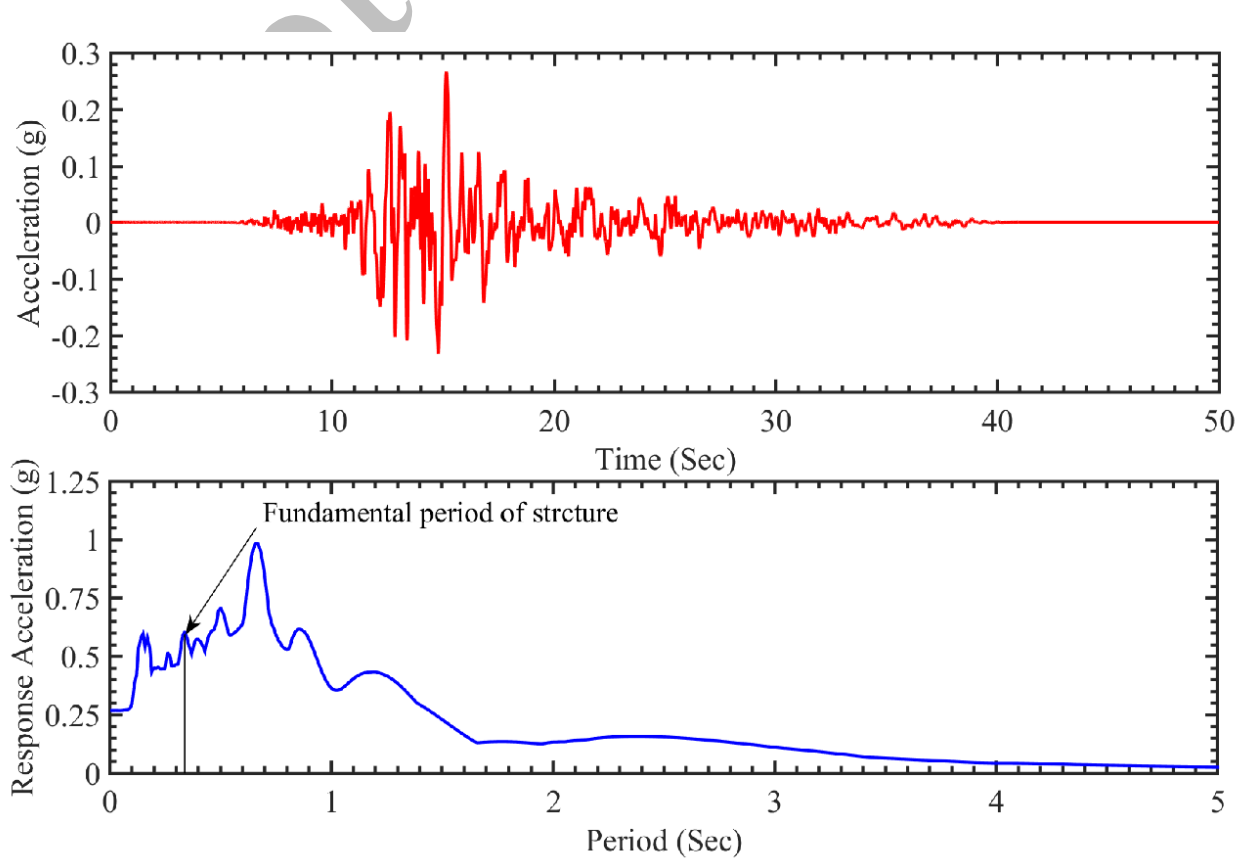

Fig. 15 Input earthquake ground motion and its response spectrum 
The IDA results for both models are shown in Fig. 16. Fig. 16 clearly shows that the conventional fibre beam-column model overestimates the collapse capacity of the RC frame. In Fig. 16, the response of the model including the effect of buckling and fatigue, shows that the structure collapses at about 0.12 drift ratio. However, the model without considering the effect of buckling shows a hardening type response, and cannot predict the structural collapse. This is extremely important in seismic fragility analysis of existing structures, as overestimating the collapse capacity of structures can have implications (e.g. catastrophic collapse of bridges) in large earthquake events (Ni Choin et al. 2016; Kashani et al. 2017).

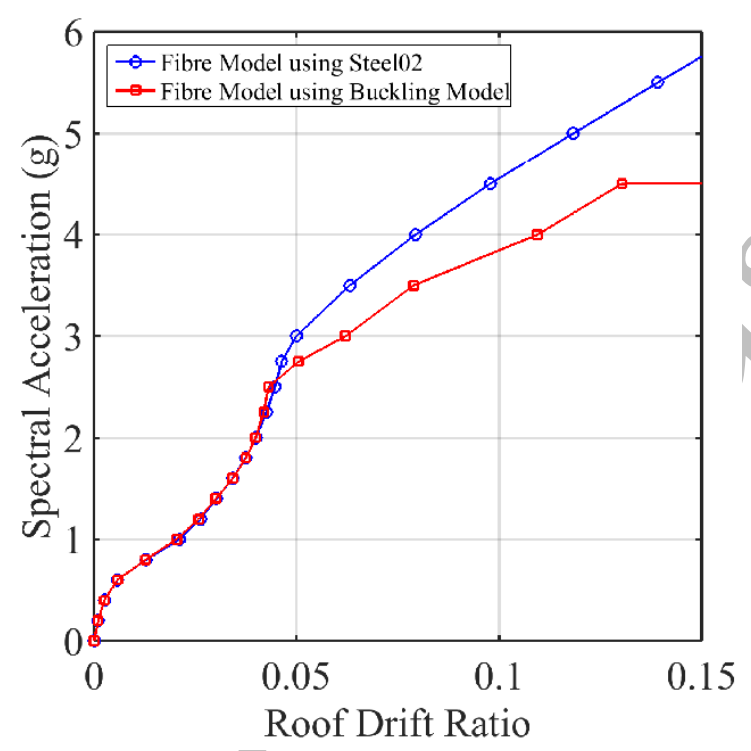

Fig. 16 The results of IDA for the RC frame with and without considering inelastic buckling of reinforcement

\section{Conclusions}

An advance modelling technique for nonlinear analysis of rectangular RC components considering the inelastic buckling and low-cycle fatigue degradation of vertical reinforcing bars is developed. The numerical model is calibrated and validated against a comprehensive set of experimental data using the UW-PEER experimental RC column dataset. The main conclusions and outcomes of this research can be summarised as follows:

1. The methodology used for prediction of buckling length of vertical reinforcement in RC columns showed a good agreement with the observed experimental results.

2. The conventional reinforcing steel material model (Steel02) can simulate the nonlinear behaviour of RC columns prior to buckling failures. However, significant degradation after severe buckling of vertical reinforcement cannot be simulated using Steel02. 
3. The proposed technique using advanced material models that account for the influence of inelastic buckling and low-cycle fatigue is able to simulate the nonlinear behaviour of RC up to significant strength loss, i.e. complete collapse.

4. The proposed model in this paper has significantly improved the existing modelling technique available in the literature. The major advantage of this modelling technique in comparison to the lumped-plasticity method is that it is generic and does not need calibration for every structure. This model is readily available in the OpenSees platform to other researchers and engineers in practice in earthquake engineering community to be used in nonlinear dynamic analysis of RC framed structures.

\section{References}

Ang BG, Priestley MJN, Park R. 1981. Ductility of Reinforced Bridge Piers under Seismic Loading. epartment of Civil Engineering, University of Canterbury.

Atalay MB, Penzien J. 1975. The Seismic Behavior of Critical Regions of Reinforced Concrete Components as Influenced by Moment, Shear and Axial Force,. University of California, Berkeley.

Bae S, Mieses A, Bayrak O. 2005. "Inelastic buckling of reinforcing bars." J of Struct Eng 131 (2): 314-321.

Bauschinger J. 1887. "Variations in the elastic limit of iron and steel." The J. of the Iron and Steel Institute 12 (1): 442-444.

Berry M, Eberhard MO. 2003. Performance Models for Flexural Damage in Reinforced Concrete Columns. Berkeley: Pacific Earthquake Engineering Research Centre.

Berry M, Parrish M, Eberhard M. 2004. Performance Database User's Manual, PEER, Univ. of Calif. Berkeley. Accessed 2013. www.ce.washington.edu/ peera1.

Berry MP, Eberhard MO. 2005. "Practical performance model for bar buckling." J Struct Eng 131 (7): 1060-1070.

Berry MP, Eberhard MO .2006. Performance modeling strategies for modern reinforced concrete bridge columns. Berkeley: Pacific Earthquake Engineering Research Centre.

Coleman J, Spacone E. 2001. "Localization issues in force-based frame elements." J Struct Eng 127 (11): 1257-1265.

Dhakal RP, Maekawa K. 2002a. "Modeling for postyield buckling of reinforcement." J of Struct Eng 128 (9): 1139-1147.

Dhakal RP, Maekawa K. 2002b. "Reinforcement stability and fracture of cover concrete in RC members." J of Struct Eng 128 (10): 1253-1262.

Filippou FC, Popov EP, Bertero VV. 1983. Effects of Bond Deterioration on Hysteretic Behavior of Reinforced Concrete Joints. Berkeley: UCB/EERC, Univ. of Calif. Berkeley.

Gomes A, Appleton J. 1997. "Nonlinear cyclic stress-strain relationship of reinforcing bars including buckling." Eng Struct 19: 822-826.

Haselton C, Liel A, Deierlein G, Dean B, Chou J. 2011. "Seismic collapse safety of reinforced concrete buildings I: assessment of ductile moment frames." J Struct Eng 481-491.

Ibarra LF, Medina RA, Krawinkler H. 2005. "Hysteretic models that incorporate strength and stiffness deterioration." Earthq Eng Struct D 1489-1511. 
Kashani MM, Barmi AK, Malinova VS. 2015b. "Influence of inelastic buckling on low-cycle fatigue degradation of reinforcing bars." Constr Build Mater 644-655.

Kashani MM, Lowes LN, Crewe AJ, Alexander NA. 2016. "Nonlinear fibre element modelling of RC bridge piers considering inelastic buckling of reinforcement." Eng Struct 116: 163-177.

Kashani MM, Lowes LN, Crewe AJ, Alexander NA. 2015a. "Phenomenological hysteretic model for corroded reinforcing bars including inelastic buckling and low-cycle fatigue degradation." Comput Struct 58-71.

Kashani MM, Málaga-Chuquitaype M, Yang S, Alexander NA,. 2017. "Influence of non-stationary content of ground-motions on nonlinear dynamic response of RC bridge piers." Bulletin of Earthquake Engineering. doi:10.1007/s10518-017-0116-8.

Kashani, MM. 2014. Seismic Performance of Corroded RC Bridge Piers: Development of a MultiMechanical Nonlinear Fibre Beam-Column Model. PhD Thesis, Bristol: University of Bristol.

Kunnath SK, Heo Y, Mohle JF. 2009. "Nonlinear uniaxial material model for reinforcing steel bars." J Struct Eng 135 (4): 335-343.

Lehman DE, Moehle JP, Mahin SA, Calderone AC, Henry H. 2004. "Experimental Evaluation of Seismic Design Provisions for Circular Reinforced Concrete Columns." J of Struct Eng 130 (6): 869879.

Lowes LN, Altoontash A. 2003. "Modeling reinforced-concrete beam-column joints subjected to cyclic loading.” J. Struct.” J of Struct Eng 129 (12): 1686-1697.

Mander JB, Rodgers GW,. 2015. "Analysis of low cycle fatigue effects on structures due to the 20102011 Canterbury earthquake sequence." Proceedings of the Tenth Pacific Conference on Earthquake Engineering. Sydney.

Menegotto M, and Pinto PE. 1973. "Method of analysis of cyclically loaded RC plane frames including changes in geometry and nonelastic behavior of elements under normal force and bending." In Preliminary Report, 13:15-22. Zurich: IABSE.

Miner MA. 1945. "Cumulative damage in fatigue.” J Appl Mech 12: A159-A164.

Moehle JP, Deierlein G. 2004. "A framework methodology for performance-based earthquake engineering." 13th WCEE. Vancouver.

Monti G, Nuti C. 1992. "Nonlinear cyclic behavior of reinforcing bars including buckling." J of Struct Eng 118 (2): 3268-3284.

Ni Choine M, Kashani MM, Lowes LN, O'Connor A, Crewe AJ, Alexander NA, Padgett JE, 2016. "Nonlinear dynamic analysis and seismic fragility assessment of a corrosion damaged integral bridge." International Journal of Structural Integrity 7 (2): 227-239.

OpenSees. 2011. "The Open System for Earthquake Engineering Simulation, ." PEER, University of California, Berkeley.

Park R, Paulay T. 1990. Use of Interlocking Spirals for Transverse Reinforcement in Bridge Columns, Strength and Ductility of Concrete Substructures of Bridges. RRU (Road Research Unit) Bulletin 84.

Park R, Priestley N, Gill W,. 1982. "Ductility of square-confined concrete columns." J Struct Div 108 (4): 929-950.

Pugh JS. 2012. Numerical simulation of walls and seismic design recommendations for walled buildings. University of Washington, $\mathrm{PhD}$ Thesis.

Rodriguez ME, Botero JC, Villa J. 1999. "Cyclic stress-strain behavior of reinforcing steel including the effect of buckling." J of Struct Eng 125 (6): 605-612. 
Saatcioglu M, Grira M. 1999. "Confinement of Reinforced Concrete Columns with Welded Reinforcement Grids." ACI Struct J 29-39.

Soesianawati MT, Park R, Priestley MJN. 1986. Limited Ductility Design of Reinforced Concrete Columns. epartment of Civil Engineering, University of Canterbury.

Spacone E, Filippou FC, Taucer FF. 1996. "Fibre beam-column model for non-linear analysis of R/C frames: part I: formulation." Earthq Eng Struct D 25: 711-725.

Spacone E, Filippou FC, Taucer FF. 1996. "Fibre beam-column model for non-linear analysis of R/C frames: part II: applications.” Earthq Eng Struct D 25: 727-742.

Tanaka H, Park R. 1990. Effect of Lateral Confining Reinforcement on the Ductile Behayior of Reinforced Concrete Column. Department of Civil Engineering, University of Canterbury.

Taucer F, Spacone E, Filippou FC. 1991. A fiber beam-column element for seismic response analysis of reinforced concrete structures. Berkeley: EERC College of Engineering, University of California.

Uriz P. 2005. Towards earthquake resistant design of concentrically braced steel structures. University of California Berkeley,PhD Thesis.

Vamvatsikos D, Cornell CA. 2002. “Incremental dynamic analysis.” Earthq Eng Struct D 491-514.

Wehbe N, Saiidi MS, Sanders D. 1998. Confinement of Rectangular Bridge Columns for Modrate Seismic Areas. National Center for Earthquake Engineering Research (NCEER) Bulletin.

Zahn FA, Park R, Priestley MJN. 1986. Design of Reinforced Bridge Columns for Strength and Ductility. Department of Civil Engineering, University of Canterbury. 


\section{Appendix A}

Table A1 Experimental column dataset

\begin{tabular}{|c|c|c|c|c|c|c|c|c|c|c|c|c|c|c|}
\hline ID & $\begin{array}{c}\text { B } \\
(\mathbf{m m}) \\
\end{array}$ & $\begin{array}{c}\mathbf{H} \\
(\mathbf{m m})\end{array}$ & $\begin{array}{c}\mathrm{L} \\
(\mathbf{m m})\end{array}$ & $\begin{array}{c}\text { Concrete } \\
\text { Cover } \\
(\mathbf{m m})\end{array}$ & $\begin{array}{c}\text { Number } \\
\text { of Bars }\end{array}$ & $\begin{array}{c}\text { Bar } \\
\text { Diamete } \\
\mathbf{r}(\mathbf{m m})\end{array}$ & $\begin{array}{c}\text { Tie } \\
\text { Spacin } \\
\text { g (mm) }\end{array}$ & $\begin{array}{c}\text { Tie } \\
\text { Diameter } \\
(\mathrm{mm})\end{array}$ & $\begin{array}{c}\text { Yield } \\
\text { Strengt } \\
\text { h (MPa) }\end{array}$ & $\begin{array}{c}\text { Ultimate } \\
\text { Strength } \\
\text { (MPa) }\end{array}$ & $\mathrm{L}_{\mathrm{eff}} / \mathrm{d}_{\mathrm{b}}$ & $\begin{array}{c}\text { Axial } \\
\text { Load } \\
(\mathrm{kN}) \\
\end{array}$ & $\begin{array}{c}\text { Int. } \\
\text { Bars } \\
\text { Y } \\
\end{array}$ & $\begin{array}{c}\text { Int. } \\
\text { Bars } \\
\text { X } \\
\end{array}$ \\
\hline 1 & 400.0 & 400.0 & 1600.0 & 24.5 & 12 & 16.0 & 100.0 & 12.0 & 427.0 & 670.0 & 6.3 & 1435.0 & 2 & 2 \\
\hline 2 & 400.0 & 400.0 & 1600.0 & 22.5 & 12 & 16.0 & 90.0 & 10.0 & 427.0 & 670.0 & 5.6 & 840.0 & 2 & 2 \\
\hline 3 & 400.0 & 400.0 & 1600.0 & 13.0 & 12 & 16.0 & 85.0 & 7.0 & 446.0 & 702.0 & 10.6 & 744.0 & 2 & 2 \\
\hline 4 & 400.0 & 400.0 & 1600.0 & 13.0 & 12 & 16.0 & 78.0 & 8.0 & 446.0 & 702.0 & 9.8 & 2112.0 & 2 & 2 \\
\hline 5 & 400.0 & 400.0 & 1600.0 & 13.0 & 12 & 16.0 & 91.0 & 7.0 & 446.0 & 702.0 & 11.4 & 2112.0 & 2 & 2 \\
\hline 6 & 400.0 & 400.0 & 1600.0 & 13.0 & 12 & 16.0 & 94.0 & 6.0 & 446.0 & 702.0 & 11.8 & 1920.0 & 2 & 2 \\
\hline 7 & 400.0 & 400.0 & 1600.0 & 13.0 & 12 & 16.0 & 117.0 & 10.0 & 440.0 & 674.0 & 7.3 & 1010.0 & 2 & 2 \\
\hline 8 & 400.0 & 400.0 & 1600.0 & 13.0 & 12 & 16.0 & 92.0 & 10.0 & 440.0 & 674.0 & 5.8 & 2502.0 & 2 & 2 \\
\hline 9 & 400.0 & 400.0 & 1600.0 & 40.0 & 8 & 20.0 & 80.0 & 12.0 & 474.0 & 721.0 & 8.0 & 819.0 & 1 & 1 \\
\hline 10 & 400.0 & 400.0 & 1600.0 & 40.0 & 8 & 20.0 & 80.0 & 12.0 & 474.0 & 721.0 & 8.0 & 819.0 & 1 & 1 \\
\hline 11 & 400.0 & 400.0 & 1600.0 & 40.0 & 8 & 20.0 & 80.0 & 12.0 & 474.0 & 721.0 & 8.0 & 819.0 & 1 & 1 \\
\hline 12 & 400.0 & 400.0 & 1600.0 & 40.0 & 8 & 20.0 & 80.0 & 12.0 & 474.0 & 721.0 & 8.0 & 819.0 & 1 & 1 \\
\hline 13 & 550.0 & 550.0 & 1650.0 & 40.0 & 12 & 20.0 & 110.0 & 12.0 & 511.0 & 675.0 & 11.0 & 968.0 & 2 & 2 \\
\hline 14 & 550.0 & 550.0 & 1650.0 & 40.0 & 12 & 20.0 & 110.0 & 12.0 & 511.0 & 675.0 & 11.0 & 968.0 & 2 & 2 \\
\hline 15 & 400.0 & 600.0 & 1784.0 & 24.0 & 10 & 24.0 & 80.0 & 12.0 & 432.0 & 0.0 & 10.0 & 646.0 & 1 & 2 \\
\hline 16 & 305.0 & 305.0 & 1676.0 & 32.0 & 4 & 22.0 & 127.0 & 9.5 & 429.0 & 657.0 & 5.8 & 534.0 & 0 & 0 \\
\hline 17 & 380.0 & 610.0 & 2335.0 & 28.0 & 18 & 19.1 & 110.0 & 6.0 & 448.0 & 731.0 & 11.5 & 615.0 & 2 & 5 \\
\hline 18 & 380.0 & 610.0 & 2335.0 & 28.0 & & 19.1 & 110.0 & 6.0 & 448.0 & 731.0 & 11.5 & 1505.0 & 2 & 5 \\
\hline 19 & 380.0 & 610.0 & 2335.0 & 25.0 & 18 & 19.1 & 83.0 & 6.0 & 448.0 & 731.0 & 17.4 & 601.0 & 2 & 5 \\
\hline 20 & 350.0 & 350.0 & 1645.0 & 29.0 & 12 & 19.5 & 152.0 & 9.5 & 455.6 & 660.0 & 7.8 & 1923.0 & 2 & 2 \\
\hline 21 & 350.0 & 350.0 & 1645.0 & 29.0 & 12 & 19.5 & 76.0 & 9.5 & 455.6 & 660.0 & 7.8 & 1923.0 & 2 & 2 \\
\hline 22 & 350.0 & 350.0 & 1645.0 & 29.0 & 12 & 19.5 & 76.0 & 6.6 & 455.6 & 660.0 & 11.7 & 961.0 & 2 & 2 \\
\hline
\end{tabular}


Table A2 Statistical information of the error in pinch combinations

\begin{tabular}{|c|c|c|c|}
\hline ID & $\Psi_{\text {kinitial }}$ & $\Psi_{\mathrm{F} 1}$ & $\boldsymbol{\Psi}_{\text {Fmax }}$ \\
\hline 1 & 0.115 & 0.062 & 0.180 \\
\hline 2 & 0.110 & 0.056 & 0.033 \\
\hline 3 & 0.318 & 0.020 & 0.041 \\
\hline 4 & 0.081 & 0.008 & 0.574 \\
\hline 5 & 0.024 & 0.006 & 0.194 \\
\hline 6 & 0.003 & 0.016 & 0.180 \\
\hline 7 & 0.072 & 0.059 & 0.236 \\
\hline 8 & 0.036 & 0.092 & 0.194 \\
\hline 9 & 0.221 & 0.142 & 0.144 \\
\hline 10 & 0.195 & 0.175 & 0.444 \\
\hline 11 & 0.115 & 0.035 & 0.331 \\
\hline 12 & 0.165 & 0.074 & 0.310 \\
\hline 13 & 0.411 & 0.113 & 0.155 \\
\hline 14 & 0.251 & 0.097 & 0.157 \\
\hline 15 & 0.211 & 0.073 & 0.306 \\
\hline 16 & 0.430 & 0.227 & 0.163 \\
\hline 17 & 0.237 & 0.012 & 0.305 \\
\hline 18 & 0.260 & 0.168 & 0.105 \\
\hline 19 & 0.408 & 0.132 & 0.433 \\
\hline 20 & 0.003 & 0.052 & 0.021 \\
\hline 21 & 0.020 & 0.022 & 0.871 \\
\hline 22 & 0.135 & 0.024 & 0.108 \\
\hline Mean & 0.174 & 0.076 & 0.249 \\
\hline Standard Deviation & 0.130 & 0.060 & 0.192 \\
\hline Max & 0.430 & 0.227 & 0.871 \\
\hline Min & 0.003 & 0.006 & 0.021 \\
\hline
\end{tabular}

